\title{
WestVirginiaUniversity
}

THE RESEARCH REPOSITORY @ WVU

Graduate Theses, Dissertations, and Problem Reports

2011

\section{Functionalization of Buckled Graphene}

Timothy C. Nelson

West Virginia University

Follow this and additional works at: https://researchrepository.wvu.edu/etd

\section{Recommended Citation}

Nelson, Timothy C., "Functionalization of Buckled Graphene" (2011). Graduate Theses, Dissertations, and Problem Reports. 2223.

https://researchrepository.wvu.edu/etd/2223

This Thesis is protected by copyright and/or related rights. It has been brought to you by the The Research Repository @ WVU with permission from the rights-holder(s). You are free to use this Thesis in any way that is permitted by the copyright and related rights legislation that applies to your use. For other uses you must obtain permission from the rights-holder(s) directly, unless additional rights are indicated by a Creative Commons license in the record and/ or on the work itself. This Thesis has been accepted for inclusion in WVU Graduate Theses, Dissertations, and Problem Reports collection by an authorized administrator of The Research Repository @ WVU. For more information, please contact researchrepository@mail.wvu.edu. 


\title{
Functionalization of Buckled Graphene
}

\author{
Timothy C. Nelson
}

\author{
Thesis \\ Submitted to the \\ College of Engineering and Mineral Resources \\ at West Virginia University \\ in partial fulfillment of the requirements \\ for the degree of
}

\section{Master of Science in Engineering}

Dr. C.D. Stinespring, Chair

Dr. R.S. Hissam

Dr. John W. Zondlo

\section{Department of Chemical Engineering \\ Morgantown, West Virginia}

2011

Keywords: Graphene, Functionalization, Surface Chemistry, Bio-Sensor 


\section{ABSTRACT}

\section{Functionalization of Buckled Graphene \\ Timothy C. Nelson}

Buckled graphene produced by the halogen based etching of $6 \mathrm{H}-\mathrm{SiC}$ provides a new route for the functionalization of the graphene surface. This surface provides an important new stepping off point in the development of molecular electronics and sensors. While the graphene surface is relatively inert, the fluorinated defect sites inherent in the buckled graphene surface yield an excellent location for chemical reactions such as nucleophilic substitution. This thesis shows the utility of the fluorinated defect sites through the well characterized diazonium reaction.

Buckled graphene films were prepared on silicon carbide substrates using inductively coupled plasma and reactive ion etching, and annealed at 1000 - $\mathrm{C}$ to coalesce the BG. The films were reacted with benzene, nitrobenzene, acetonitrile, or a nitrophenyl diazonium salt solution. The diazonium salt was chosen due to its known reaction with graphene produced by other methods. Consequently, reaction of the diazonium with buckled graphene would provide a basis for comparing the reactivity of the surface with these other forums of graphene. The interactions of buckled graphene with the other species were investigated as they represent either constituent parts of the diazonium salt or the solvent. The reacted surfaces were analyzed by X-ray photoelectron spectroscopy, which reveals changes in the surface chemical state due to the functionalization of the buckled graphene by each species.

Each reaction yielded significant $\pi-\pi$ bonding, while the diazonium salt reaction produced additional covalently bonded phenyl groups on the buckled graphene surface. The covalent reaction site was shown to be the surface fluorinated defect site. This observation illustrates the utility of the buckled graphene surface in the functionalization of graphene. Moreover, it provides additional confirmation of the nature of the buckled graphene surface. 


\section{ACKNOWLEDGEMENTS}

I have many to thank as I finish this work in West Virginia. First, though, I must acknowledge my wife, Kate Nelson, for all the support she gave throughout this time in our lives. I truly would not be here without her love and efforts, and I am immensely grateful and thankful for all she endured in this period.

My advisor, Dr. Charter D. Stinespring led me to and through this project. His expertise in this area of my interests and experience vastly aided my growing understanding of the research of his laboratory.

My committee Dr. Robin Hissam and Dr. John Zondlo worked quickly to review and aid my research capabilities.

My labmates, Tobias Denig and Srikanth Raghavan spent many hours sharing their knowledge and know-how to help out the new guy in the lab. I lean on their research and the many lab discussions.

The Chemical Engineering department enjoys the help of two ladies, Bonnie Hemlock and Linda Rogers. Both dropped whatever they were doing to help me more times than I wish to admit, and I am very grateful for all of their help.

I thank the undergraduate class of 2009, and the straggler left behind. I didn't know what I was getting into, and your help my 'junior year' was greatly appreciated. And to the straggler, thanks for the all the fun in the woods while I was left straggling behind.

I thank my good friends; for the talk and understanding and a chance to escape. And I thank the growing understanding of my son, Loki. Loki, I am very excited to return to being your full-time daddy, if you don't remember when last I was.

Finally, I would like to thank the NASA - WV Space Grant Consortium and the WVU Program to Stimulate Competitive Research for funding this project. 


\section{TABLE OF CONTENTS}

TITLE PAGE i

$\begin{array}{ll}\text { ABSTRACT } & \text { ii }\end{array}$

ACKNOWLEDGEMENTS iv

TABLE OF CONTENTS v v

TABLE OF FIGURES/TABLES vii

CHAPTER 1: BACKGROUND AND INITIAL PROBLEM STATEMENT 1

CHAPTER 2: LITERATURE REVIEW

2.1 Preparation and Characterization of Graphene 6

$\begin{array}{lll}2.2 & \text { Synthesis Research at WVU } & 7\end{array}$

$\begin{array}{ll}2.3 & \text { Doping and Surface Functionalization }\end{array}$

\section{CHAPTER 3: EXPERIMENTAL METHODS}

$\begin{array}{lll}3.1 & \text { Sample Preparation } & 15\end{array}$

3.2 X-Ray Photoelectron Spectroscopy 16

CHAPTER 4: EXPERIMENTAL RESULTS AND DISCUSSION

4.1 The Buckled Graphene Surface 18

$\begin{array}{lll}4.2 & \text { Adsorption of Benzene } & 19\end{array}$

$\begin{array}{lll}4.3 & \text { Adsorption of Nitrobenzene } & 21\end{array}$

4.4 Adsorption of Acetonitrile 23

4.5 Adsorption of Nitrobenzenediazonium Tetrafluoroborate 26

4.6 Implications of this Research 28

\section{CHAPTER 5: CONCLUSIONS}


$\begin{array}{lll}5.1 & \text { Conclusions } & 30\end{array}$

5.2 Future Work 34

REFERENCES 35 


\section{List of Figures}

Figure 1.1 The first Brillioun zone and carrier population of graphene 2

Figure 2.1 Optical and AFM images of graphene flakes $\quad 6$

$\begin{array}{lll}\text { Figure 2.2 XPS spectra of plasma processed silicon carbide } & 8\end{array}$

Figure 2.3 XPS and surface sensitive fluorine spectra of buckled graphene $\quad 8$

Figure 2.4 Schematic of the buckling of graphene 9

$\begin{array}{lll}\text { Figure 2.5 RHEED of SiC and buckled graphene } & 10\end{array}$

$\begin{array}{lll}\text { Figure 2.6 Reciprocal lattices of SiC and Graphite } & 10\end{array}$

$\begin{array}{lll}\text { Figure } 2.7 & \text { Surface doping of diamond } & 11\end{array}$

$\begin{array}{lll}\text { Figure } 2.8 & \text { F4-TCNQ on graphene } & 12\end{array}$

$\begin{array}{lll}\text { Figure 2.9 The diazonium reaction on graphene } & 13\end{array}$

Figure 2.10 Schematics of $S_{N} 1$ and $S_{N} 2$ reactions $\quad 14$

$\begin{array}{lll}\text { Figure } 3.1 \quad \text { Schematic of ICP/RIE etching process } & 15\end{array}$

Figure 3.2 Principle of X-ray photoelectron spectroscopy 16

$\begin{array}{lll}\text { Figure 4.1 C1s XPS of buckled graphene } & 18\end{array}$

$\begin{array}{lll}\text { Figure } 4.2 & \text { F1s XPS of buckled graphene } & 19\end{array}$

Figure 4.3 C1s XPS of the benzene reacted buckled graphene 19

Figure 4.4 F1s XPS of the benzene reacted buckled graphene 20

Figure 4.5 C1s XPS of the nitrobenzene reacted buckled graphene 21

Figure 4.6 F1s XPS of the nitrobenzene reacted buckled graphene 22

Figure 4.7 N1s XPS of the nitrobenzene reacted buckled graphene 23

Figure 4.8 C1s XPS of the acetonitrile reacted buckled graphene 24

Figure 4.9 F1s XPS of the acetonitrile reacted buckled graphene 24 
Figure 4.10 N1s XPS of the acetonitrile reacted buckled graphene

Figure 4.11 C1s XPS of the diazonium reacted buckled graphene

Figure 4.12 F1s XPS of the diazonium reacted buckled graphene

Figure 4.13 N1s XPS of the diazonium reacted buckled graphene 


\section{CHAPTER 1}

\section{BACKGROUND AND PROBLEM STATEMENT}

Carbon takes several interesting allotropic forms including amorphous, diamond, and graphite. Of these, graphite, the most stable, is a semi-metal used in many differing applications including pencils, batteries, lubricants and steelmaking. ${ }^{1}$ Graphite consists of layers of carbon sheets. The carbon of each sheet binds into hexagonal honeycomb rings with sigma bonds forming the inter-atomic $\mathrm{sp}^{2}-\mathrm{C}$ bonds and $\pi$-bonds above and below the plane forming the $\mathrm{p}$ orbitals. Sheets are bound together using van der Waals-like forces. ${ }^{2}$

Peierls and Landau ${ }^{3,4}$ deemed the separation of individual sheets of graphite a physical impossibility in 1935 and 1937. At the time, experimental evidence suggested that all monolayers yield to thermal fluctuations and inter-atomic forces. Put simply, they either fall apart or "glom" together, but do not form monolayers. As a result, physicists theorized on the properties of monolayers without hope of seeing actual materials.

The first report of graphene came in 2004 by Geim et al. ${ }^{6}$ They reported the mechanical exfoliation of graphene from bulk graphite, and provided a first look at the physical properties of the material. The early samples showed high quality, high carrier mobility, and susceptibility to the electric field effect. This first report started the growing interest in what most scientists previously believed impossible. It is for this work that Geim and Novaslov recently received the 2010 Nobel Prize in Physics. ${ }^{7}$

Since its discovery, graphene has been proposed for use in a wide variety of applications including molecular electronics as well as chemical- and bio-sensors. The development of such 
devices depends critically on tuning the electrical properties of graphene by functionalizing its surface with a variety of molecules.

Graphene is a gapless semiconductor with several interesting properties as illustrated in Figure 1a. The first major observation is that the resting mass of the charge carriers is zero, giving the speed of the carriers a linear relationship between the energies of the conduction and valence bands with momentum. Such a relationship implies that the charge carriers travel at constant velocity, the Fermi velocity, and allows use of the Dirac rather than the Schrödinger equation. The second conclusion comes in part from the first. As all the carriers move at the same speed and as they are limited to two dimensions, they have exceptionally long mean free paths. The mean free path of an electron or hole is the average distance the carrier travels before collision with a second carrier. The

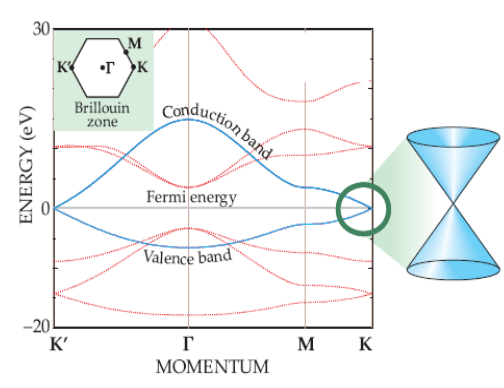

(a)

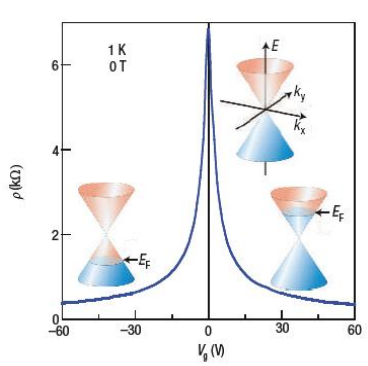

(b)

Figure 1.1. a) The edge of the first Brillouin zone shows the gapless meeting of the conduction and valence bands. b) A magnetic field applied perpendicular to a graphene surface shifts the population up or down. [ref. 2,5]

mean free path of a carrier depends on the size, number and relative velocities of carriers. The mean free path of an electron in graphene is on the micrometer scale. ${ }^{2}$

The gapless semiconducting nature of graphene implies that the material is conductive at any temperature above absolute zero due to the ballistic movement of electrons inside graphene. That is to say that at any temperature above zero there will be electrons thermally excited to the conduction band, which will travel without scattering at high velocity for relatively large distances under an applied potential. None-the-less, like other semiconductors, it is desirable to 
modify the number and type of charge carriers in graphene. For normal semiconductors this is achieved by substituting dopant atoms of different atomic groups into the crystal structure. This approach would create high levels of defects in the graphene monolayer and is not feasible. While some research suggests the utilization of bipolar electric fields to switch from $\mathrm{n}$ to $\mathrm{p}$-type conductivity (Figure 1b) a second possibility is the use of surface dopants. ${ }^{8}$ Doping techniques by functionalizing the surface present a new and viable doping technique for graphene.

The major foreseeable limitation in the evolution of graphene electronics concerns graphene synthesis methods. To date most of the key results for graphene have been demonstrated using mechanically exfoliated graphene flakes. Typically dimensions for these are on the order of microns. Moreover, these flakes must be placed on an insulating substrate in order to construct usable electronic devices. While some progress has been made using pick and place methods, ${ }^{9}$ it is difficult to imagine a semiconductor industry based on such procedures.

In related research at West Virginia University, Raghavan has demonstrated the synthesis of buckled graphene films using halogen-based plasma etching of $6 \mathrm{H}-\mathrm{SiC} .{ }^{10}$ In addition, Denig ${ }^{11}$ has demonstrated that that the buckled graphene films have an electrical conductivity comparable to exfoliated graphene. Moreover, under fairly crude conditions, it has been shown that metal contacts with low interfacial resistance can be produced. The significance of these results is that graphene films of controlled thickness and excellent electrical properties can now be produced on insulating substrates using scalable methods that are well understood by the electronics industry. The next step in the development of the buckled graphene films is to demonstrate the control of electrical properties by functionalizing the surface.

The focus of the research described in this thesis is the functionalization of the buckled graphene surface by several molecular groups and the chemical characterization of the 
functionalized surface. The electronic properties of the functionalized materials are left to future research. Specifically, this investigation seeks to develop an understanding of the chemical change of both the surface and adspecies that occur upon functionalization. Bekyarova et al. ${ }^{12}$ have shown that epitaxial graphene formed by evaporation of $\mathrm{Si}$ form $4 \mathrm{H}-\mathrm{SiC}$ can be functionalized using 4-nitrophenyl diazonium tetrafluoroborate. As a basis for comparing the buckled graphene with "normal" graphene, the present study has used x-ray photoelectron spectroscopy (XPS) to investigate the reaction of 4-nitrophenyl diazonium tetrafluoroborate with the buckled graphene surface. To complement these studies and provide a broader understanding of the adsorption of diazonium salt, benzene, nitrobenzene, and acetonitrile was also investigated. Benzene and nitrobenzene were included as simpler molecules representative of components of the chosen diazonium salt. Adsorption of acetonitrile was included since the diazonium salt was dissolved in acetonitrile for the diazonium reaction.

In Chapter 2, the synthesis methods currently used to produce normal graphene are reviewed, the plasma based method of producing buckled graphene is described, and the results of doping and functionalization studies for normal graphene are summarized. In Chapter 3, the experimental methods used in the present research are described, and in Chapter 4, the experimental results are presented and discussed. Moreover, the implications of these results for sensors and molecular electronics are given. Finally, in Chapter 5, conclusions and recommendations for future work are given. 


\section{CHAPTER 2}

\section{LITERATURE REVIEW}

\subsection{PREPARATION AND CHARACTERIZATION OF GRAPHENE}

The mechanical exfoliation technique to prepare graphene quickly garnered the name 'sticky-tape method' due to its unique nature. Researchers applied and stripped tape from either pieces of highly ordered pyrolytic graphite (HOPG) or lines drawn with graphite pencils. The tape removed thin layers of graphene from the bulk. After applying and removing subsequent pieces of tape to the initial strip, the final graphene bearing tape was dissolved allowing the flakes to float free. Wafers of $\mathrm{Si}$ with a $300 \mathrm{~nm}$ thick $\mathrm{SiO}_{2}$ surface layer were used to collect the floating flakes from the solvent. ${ }^{6}$

Thin flakes of graphene are transparent to the eye, but were revealed and the thicknesses roughly measured by optical microscopy of the $\mathrm{SiO}_{2} / \mathrm{Si}$ substrate as seen in Figure $2.1 \mathrm{a}^{6} \quad 300$ $\mathrm{nm} \mathrm{SiO}_{2}$ is violet in white light do to optical interference. The addition of one or more layers of

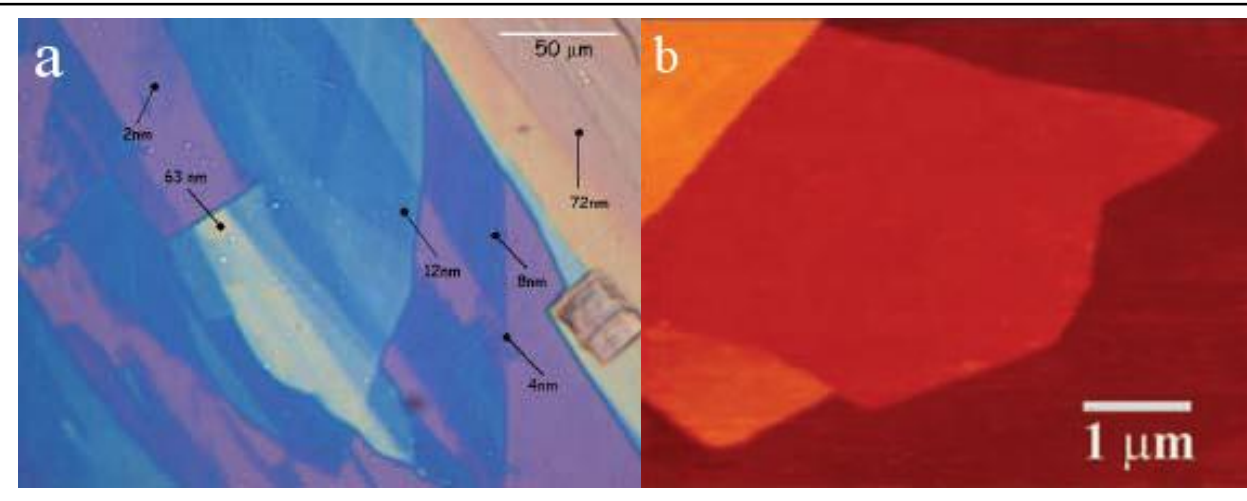

Figure 2.1 a) Optical microscope image of few layer graphene $\sim 3 \mathrm{~nm}$ thick on silicon oxide. b) AFM image of graphene flakes, the bottom showing single-few layer graphene. Color Code: dark brown, $\mathrm{SiO}_{2}$ surface; brown-red (central area), $0.8 \mathrm{~nm}$ height; yellow-brown (bottom left), $1.2 \mathrm{~nm}$; orange (top left), $2.5 \mathrm{~nm}$. The film in the lower left represents a folded single layer with differential height $\sim 0.4 \mathrm{~nm}$. [ref 6] 
graphene to the optical path shifts the interference color to larger wavelengths (violet-blues to blue) with increasing thickness. The thickness of graphene was further characterized by atomic force microscopy (AFM). A typical AFM image of an un-exfoliated graphene flake is shown in Figure 2.1b. Note that the flake has regions of varying thickness and it is only the small folded region at the lower left which has monolayer thickness. In general such flakes are differentiated into monolayer graphene, bi-layer graphene, and few layer graphene. At ten layers graphene takes on the properties of bulk graphite.

The large numbers of applications for graphene demand a more robust method for the preparation of graphene. This challenge has not been fully met, but several techniques under current research show promise. Among these are chemical exfoliation and chemical vapor deposition. Thermal annealing of $\mathrm{SiC}$ at temperatures between 1100 and $1500^{\circ} \mathrm{C}$ has also been found to yield graphitic surface layers. Both the chemical exfoliation and CVD approach are limited by the fact that the graphene must be transferred from a conducting growth substrate to a nonconducting device substrate. The thermal approach produces graphene on an insulating $\mathrm{SiC}$ substrate, but the process may be limited by the need to precisely control high annealing temperatures over large areas for wafer scale production of graphene.

\subsection{SYNTHESIS RESEARCH AT WVU}

The graphene films used in this research were prepared using halogen based $\left(\mathrm{CF}_{4}\right)$ plasma etching to selectively etch $\mathrm{Si}$ from $6 \mathrm{H}-\mathrm{SiC}$ (Cree Inc.). The resulting carbon-rich film is annealed at $1000^{\circ} \mathrm{C}$. This reconstructs the surface to form the graphene film while desorbing all but the most tightly bound halogens. 


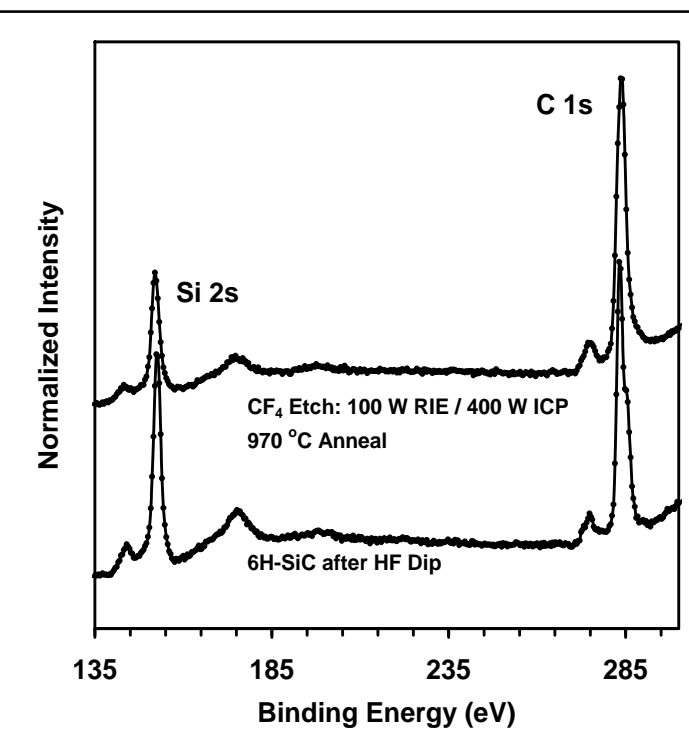

(a)

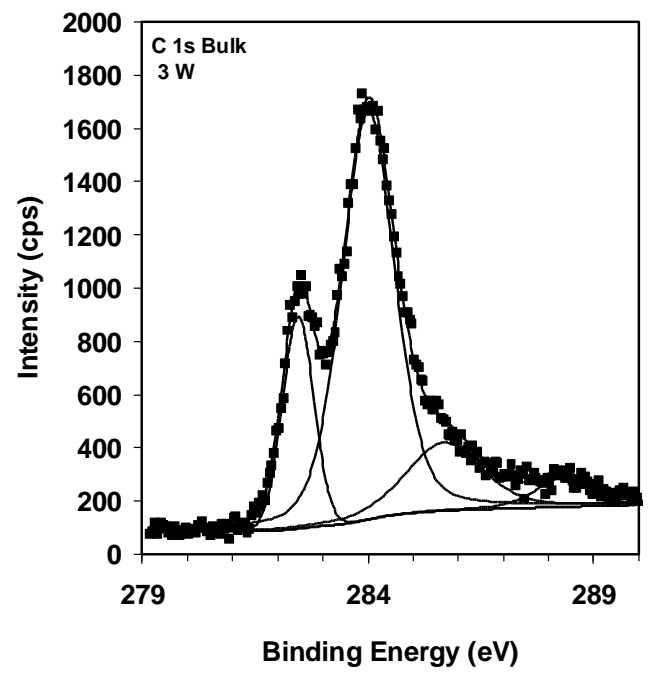

(b)

Figure 2.2 a) XPS survey specta showing the $\mathrm{Si} 2 \mathrm{~s}$ and $\mathrm{C} 1 \mathrm{~s}$ peaks for the $6 \mathrm{H}$-SiC surface before and after plasma etching and annealing. b) C1s XPS spectra of the etched and annealed surface. [ref 10$]$

Figure 2.2a shows a portion of the x-ray photoelectric spectrum (XPS) for the surface before and after the etching. Before the etching the intensities of the Si 2 s and $\mathrm{C}$ 1s peaks are indicative of stoichiometric $\mathrm{SiC}$. After etching and annealing, the decrease in the Si2s intensity relative to that of the $\mathrm{C} 1 \mathrm{~s}$ is indicative of the selective etching of $\mathrm{Si}$.

Figure $2.2 \mathrm{~b}$ shows the $\mathrm{C} 1 \mathrm{~s}$ XPS peak for the etched and annealed surface. The peak at 282.5eV corresponds to the substrate. The peak at $284.1 \mathrm{eV}$ corresponds to p-type graphene $\left(\mathrm{sp}^{2}-\mathrm{C}\right)$. The peak at $285.7 \mathrm{eV}$ corresponds to $\mathrm{sp}^{2} \mathrm{C}$, which is denoted as $\mathrm{C}_{\mathrm{C}}$. While the peak at $288.1 \mathrm{eV}$ corresponds to $\mathrm{sp}^{3}-\mathrm{C}$ bound to an $\mathrm{F}$ atom and denoted as $\mathrm{C}_{\mathrm{F}}{ }^{39}$. The later three peaks are all related to the graphene film. The ratio of the graphene related peaks to the substrate peak reveals that this film is two to three layers thick. ${ }^{10}$ This is just slightly thicker than most films produced under similar conditions. 
Figure 2.3 shows F 1s spectra for this sample taken using bulk (a) and surface sensitive (b) analysis modes. On going from bulk to surface sensitive mode, careful analysis show that the

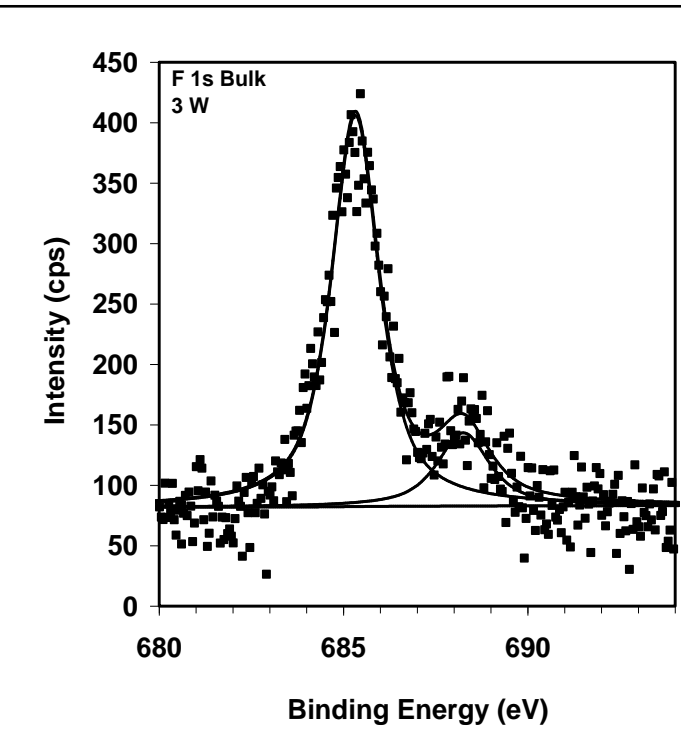

(a)

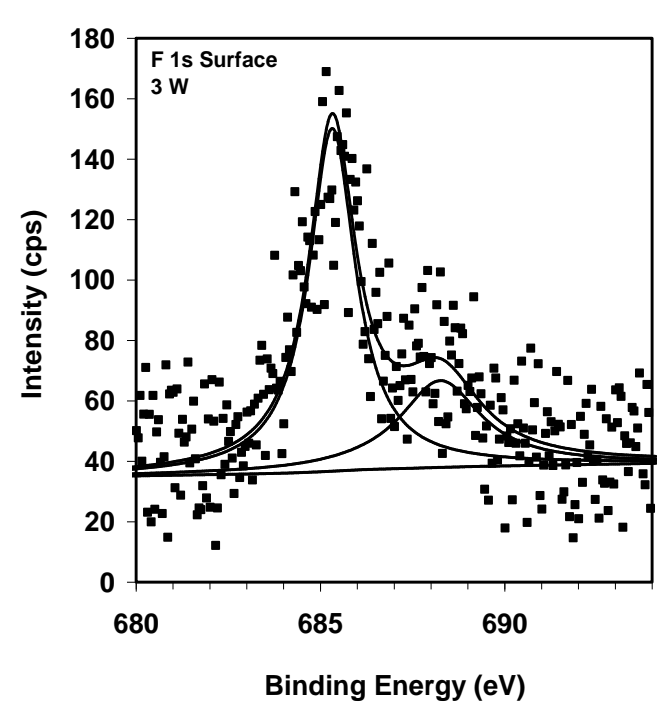

(b)

Figure 2.3. a) Bulk mode XPS of F1s peaks for buckled graphene film. b) Corresponding spectrum taken in a surface sensitive analysis mode. [ref 10]

peak at lower binding energy decreases in intensity relative to the higher binding energy peak.

This indicates that the lower binding energy peak is due to a sub-surface species while that at higher binding energy is due to a surface species. These F species are both associated with the $\mathrm{C}_{\mathrm{F}}$ species discussed in the context of the $\mathrm{C} 1 \mathrm{~s}$ spectrum. Recent experimental and computational results have shown that the $C_{F}$ species is a unique specific defect in the graphene structure. ${ }^{38}$ This defect is illustrated in figure 2.4a. It consists of two coupled $\mathrm{sp}^{3}$ hybridized $\mathrm{C}$ atoms each bound to a $\mathrm{F}$ atom, one $\mathrm{F}$ atom is above the surface and other is below the surface. ${ }^{38}$ When inserted into the $\mathrm{sp}^{2}-\mathrm{C}$ network, this defect produces a 'buckled' graphene surface shown in Figure $2.4 \mathrm{~b} .{ }^{38}$ It is this coupling of the $\mathrm{sp}^{3}$ bonded $\mathrm{C}$ atoms which buckles the planer graphene surface. The $\mathrm{C}_{\mathrm{C}}$ species is discussed in the context of the $\mathrm{C} 1 \mathrm{~s}$ spectra. In Figure $2.4 \mathrm{a}$ are $\mathrm{sp}^{2}-\mathrm{C}$ atoms bound to these $\mathrm{sp}^{3}-\mathrm{C}$ atoms of the $\mathrm{C}_{\mathrm{F}}$ defect. 
a.

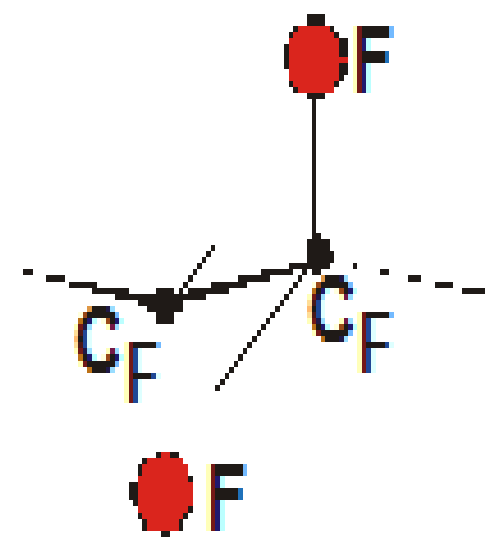

b.
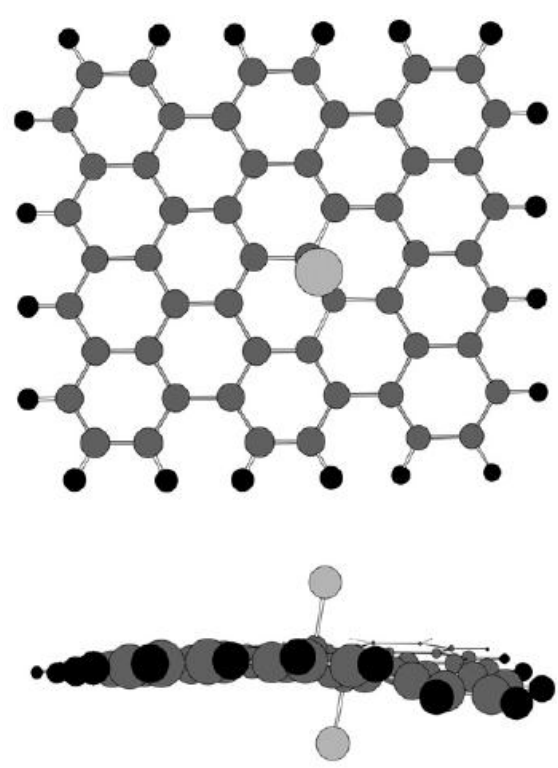

Figure 2.5

shows the reflection

high energy electron

diffraction (RHEED)

pattern for the buckled

graphene surface for

the $[1 \overline{1} 00]$ azimuthal

direction. ${ }^{10}$ Patterns

for both the $\mathrm{SiC}$

substrate and the

graphene overlayer

can be seen here.

Although this pattern

reveals a level of strain

Figure 2.4 a) The $\mathrm{C}_{\mathrm{F}}$ defect which consists of two coupled $\mathrm{sp}^{3}-\mathrm{C}$ atoms each bound to an $\mathrm{F}$ atom with one $\mathrm{F}$ atom sitting above the surface and the other below the surface. The sp3-C atoms bound to these sites are referred to as $\mathrm{C}_{\mathrm{C}}$ atoms. $\mathrm{b}$ ) A top down (above) and edge (below) view of the $\mathrm{C}_{\mathrm{F}}$ defect in the graphene lattice. A major effect of this defect is to buckle the normally flat carbon plane. Only one $\mathrm{F}$ atoms is visible in the top down view since the $\mathrm{F}$ atoms are situated one above the other. [ref 38]

in the graphene, it is very consistent with RHEED patterns reported by Moreau ${ }^{40}$ for graphene produced by high temperature annealing of $\mathrm{SiC}$. It is not clear at this time if the strain is due to the buckling of the surface or possibly due to coupling to the substrate surface.

As a final note, Denig ${ }^{11}$ has measured the electrical conductivity of these buckled graphene films using the transmission line method. These results show that the conductivity is a strong function of annealing temperature

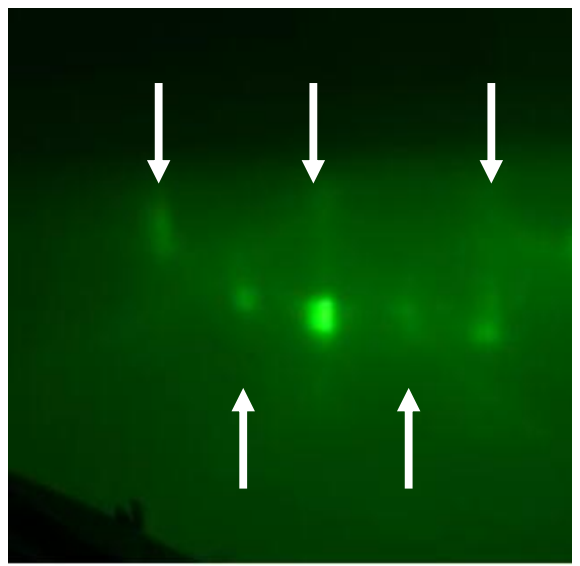

Figure 2.5 a) RHEED pattern along the $[1 \overline{1} 00]$ direction showing the spots due to $6 \mathrm{H}-\mathrm{SiC}$ substrate (down arrows) and additional spots due to the graphene overlayer (up arrows). [ref 10] 
and the number of graphene layers. In general, films similar to those used here have electrical conductivities comparable to those of single layer exfoliated graphene films.

\subsection{DOPING AND SURFACE FUNCTIONALIZATION}

In conventional semiconductor materials, dopant atoms are incorporated as impurities into crystal structures, randomly replacing atoms throughout the crystal or thin film. The dopants typically differ in atomic group from the primary constituents and either have extra electrons, which become free electrons, or are deficient in electrons and yield holes. The former are classified as n-type semiconductors, while the latter are classified as p-type. While a typical semiconductor is insulating, n-doped material contains filled energy levels very close to the edge

of the conduction band, resulting in a very easy transition to a conducting sample. P-doping removes the highest energy electrons from the valence band and leaves holes as the majority carrier in the material.

Surface doping differs in that dopants are not inserted into the crystal structure, but sit at the surface as "solvated electrochemical species, isolated molecules, or solid adsorbates." ${ }^{8}$ P-type doping in this manner is most easily shown graphically as in Figure 2.6, where the lowest unoccupied molecular orbital must be just above or beneath the valence band of the semiconductor. In such a system, electrons from the valence band move to the lowest unoccupied molecular orbital of the surface species. Figure 2.6 shows this process for diamond. For graphene systems, the top of the valence band is at the Fermi level, and the removal of electrons from the valence band results in an unfilled energy levels. The band gaps of traditional 
semiconductors

are of prohibited

energies of

electrons where

the gap

introduced into

surface doped

graphene is of

emptied allowed

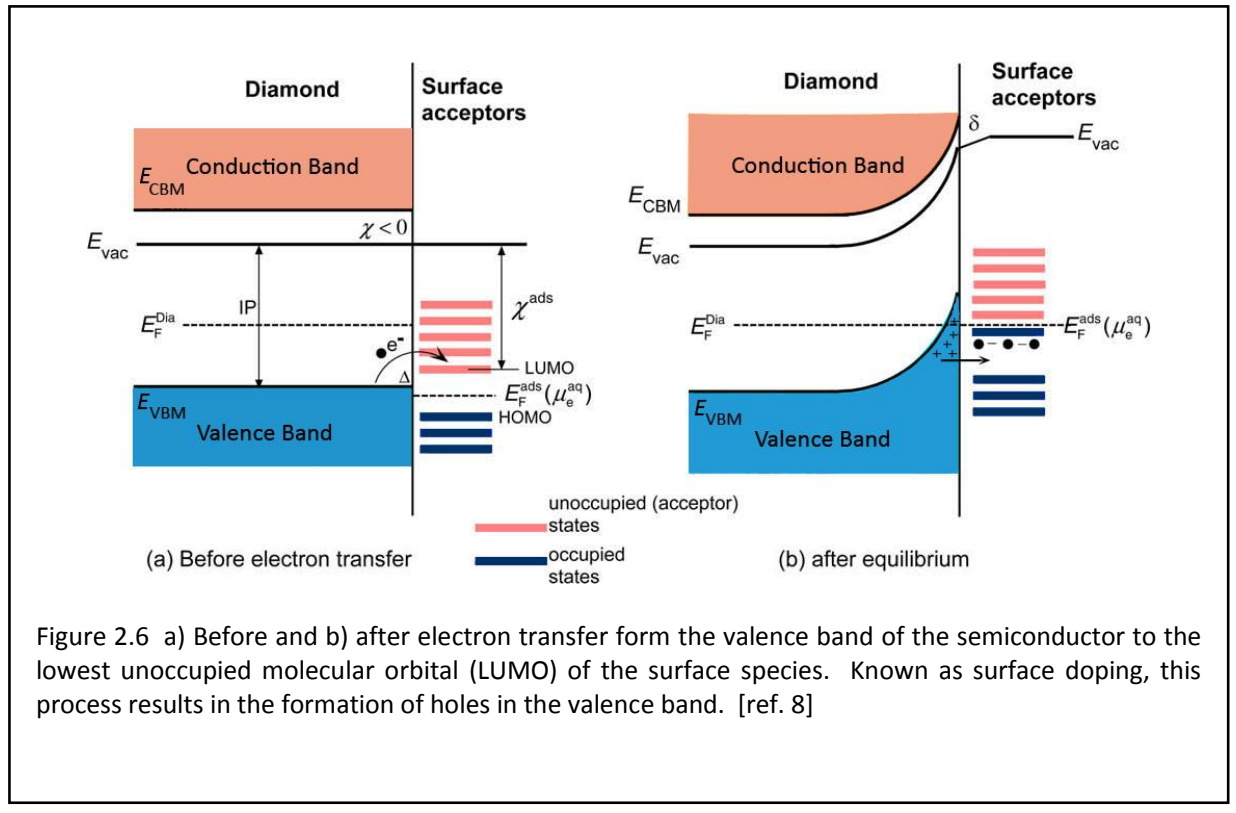

energy levels.

Surface transfer doping by the atmospheric molecules $\mathrm{H}, \mathrm{H}_{2}, \mathrm{OH}, \mathrm{H}_{2} \mathrm{O}, \mathrm{O}, \mathrm{O}_{2}$, and $\mathrm{NO}_{2}$ has been shown to be possible; ${ }^{15}$ however, these species lack sufficient electron affinity to induce a gap in the material. Instead, more electronegative molecules were required. Hydroxyl groups are of some interest, but the group will not accept a second electron from graphene, and therefore cannot surface dope the material. ${ }^{15}$ Of the more electronegative molecules suggested, tetrafluorotetracyanoquinodimethane (F4-TCNQ) (Figure 2.7a) has shown some promise. ${ }^{16}$ The molecule was shown to be highly electron withdrawing in previous uses, ${ }^{17-19}$ and was successfully used with graphene. When graphene was coated by F4-TCNQ, as shown in 2.7b, a gap was shown to open as the F4-TCNQ thickness increased. As demonstrated by the valence band photoelectron spectra shown in Figure $2.7 \mathrm{c}$, a narrow band of $\sim 0.7 \mathrm{eV}$ appeared for a $0.1 \mathrm{~nm}$ coating of F4-TCNQ. The gap increased to $1.3 \mathrm{eV}$ when the coating increased to $\sim 0.2 \mathrm{~nm}$, but only modestly increased with further additions of F4-TCNQ. 


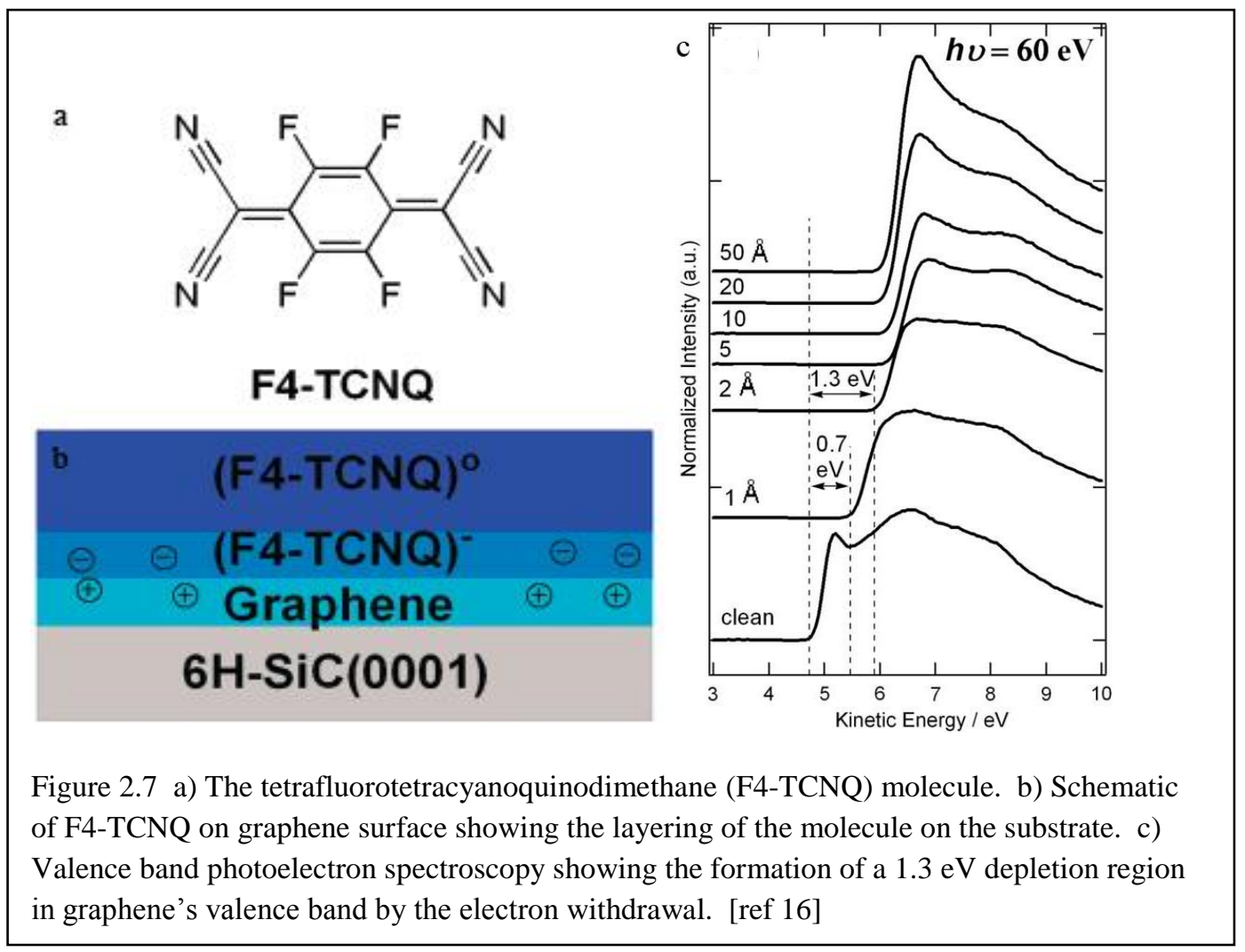

Although surface transfer doping offers proven doping ability, substitutional and covalent reactions give different options. Sulfur substitution was computationally shown to induce a $0.3 \mathrm{eV}$ band gap in graphene by deformation of the graphene structure. ${ }^{20}$ The slightly longer carbon-sulfur bonds cause the sulfur to rise a small distance above the surface, and this distortion was thought to produce the small band gap. ${ }^{20}$ A second computational study by the same group looked at the cycloaddition of azomethine ylides to graphene. ${ }^{21}$ They reported that $\mathrm{sp}^{3}$ hybridized graphene would show a band gap, but that the ylides only react with graphene at the Stone Wales defect sites, a combinational defect in graphene and carbon nanotubes in which one ring contains only five carbons and an adjacent ring consists of seven. ${ }^{22}$ 
Another covalent reaction that creates a $\mathrm{sp}^{3}$ hybrized graphene and is suggested to yield a band gap is the diazonium reaction. This process is illustrated in figure $2.8 .^{12}$ This reaction is frequently used to covalently attach phenyl groups to metals, silicon and graphitic materials. Nitro-phenyl groups attached to graphene were shown to be chemically, electrically and thermally stable. The resistivity of the reacted graphene was significantly increased by this reaction. ${ }^{12}$ It is interesting to note that other $\mathrm{R}$ ground could be attached in this manner.

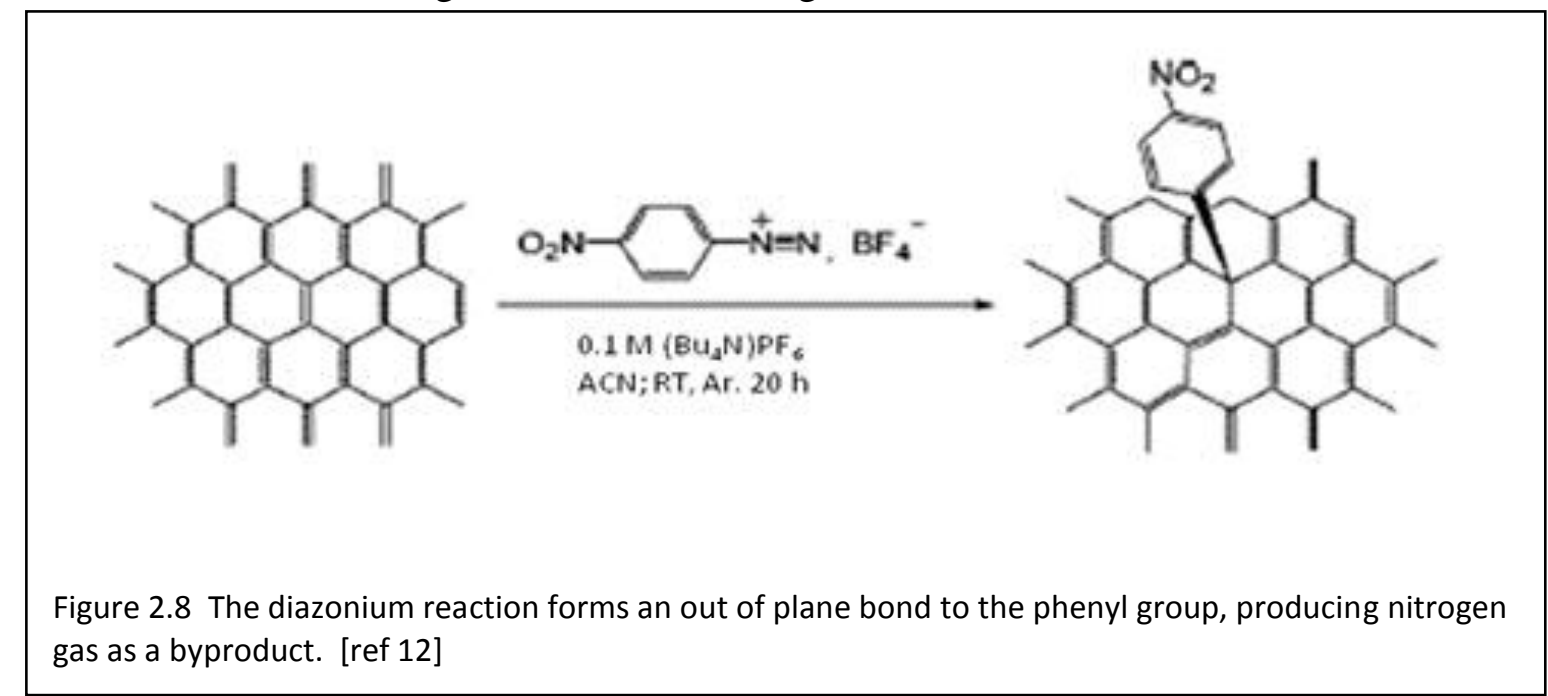

Bon, et al. prepared graphene by chemical exfoliation of graphite and then exposed the graphene to a $\mathrm{CF}_{4}$ plasma to form $\mathrm{sp}^{3}$ hybridized carbon on the surface. ${ }^{23}$ The fluorinated carbon was then easily reacted with the nucleophilic amine group in butylamine. The fact that nucleophilic groups replace halides suggests either a $S_{N} 1$ or $S_{N} 2$ reaction. Figure 2.9 shows examples of $S_{N} 1$ and $S_{N} 2$ type reactions. For $S_{N} 1$ reactions, no change in stereochemistry is required. The $\mathrm{S}_{\mathrm{N}} 2$ reaction flips the stereochemistry of the molecule as the nucleophile enters from the site opposite that of the exiting group. 


\section{a}

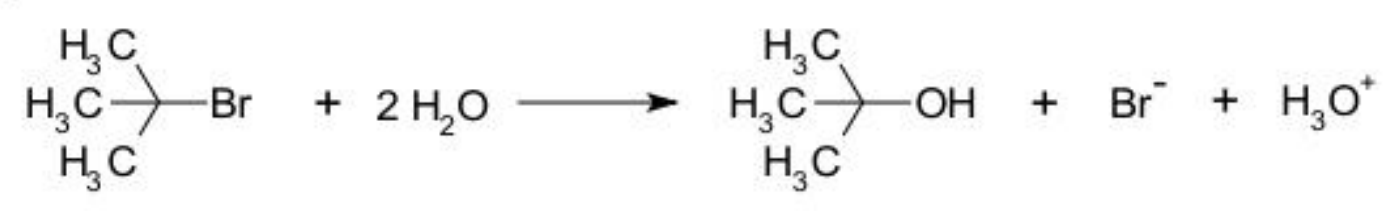

b

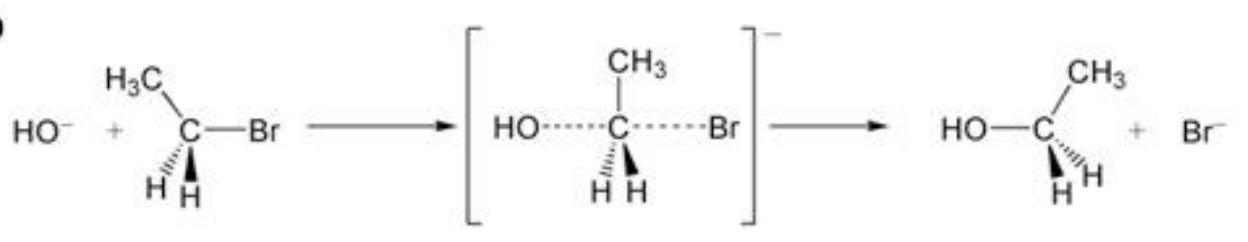

Figure 2.9 a) The $\mathrm{S}_{\mathrm{N}} 1$ reaction requires no change in stereochemistry. b) The $\mathrm{S}_{\mathrm{N}} 2$ reaction 'flips' the stereochemistry of the molecule as the nucleophile approaches from the side opposite that of the leaving group.

As described previously, the 'buckled graphene' used in the present research and described more fully by Ragavan. ${ }^{10}$ have one F atom above the surface and the other below the surface. For the upper atom $S_{N} 1$ type reactions should dominate. For the lower atom, $\mathrm{S}_{\mathrm{N}} 2$ reactions should dominate. If other $\mathrm{S}_{\mathrm{N}} 1$ or $\mathrm{S}_{\mathrm{N}} 2$ reactions occur changes in the intensity of one or both of the F peaks should be observed. Moreover, these reactions should allow for easy surface doping of graphene and the possibility of attaching long R-groups capable of selective response to chemicals in their environments or other stimulus. In this way buckled graphene gives a new pathway to graphene based sensors and devices. 


\section{CHAPTER 3}

\section{EXPERIMENTAL METHODS}

\subsection{SAMEPLE PREPARATION}

As described in section 2.1, the buckled graphene films were $6 \mathrm{H}-\mathrm{SiC}$. . In the work presented here, ICP-RIE was performed using a Trion Technology Phantom 3 ICP RIE with 300 W ICP and 400 W RIE power. A schematic of the process is shown in Figure 3.1. The process was completed in 12 minutes at a pressure of 25 mTorr and a flow of $20 \mathrm{sccm}$ of $\mathrm{CF}_{4}$. Four pieces of $6 \mathrm{H}-\mathrm{SiC}$ were attached to the center of a four inch silicon wafer by carbon tape for each cycle. After etching, the samples were annealed at $1000^{\circ} \mathrm{C}$ under ultrahigh vacuum conditions for $1 \mathrm{hr}$ to reconstruct the carbon rich layer and form the buckled graphene film

The samples used in this study were supplied as 2inch wafers by Cree, Inc. and diced by American Precision Dicing to half centimeter square pieces of $257 \mu \mathrm{m}$ in thickness. Prior to the plasma process all

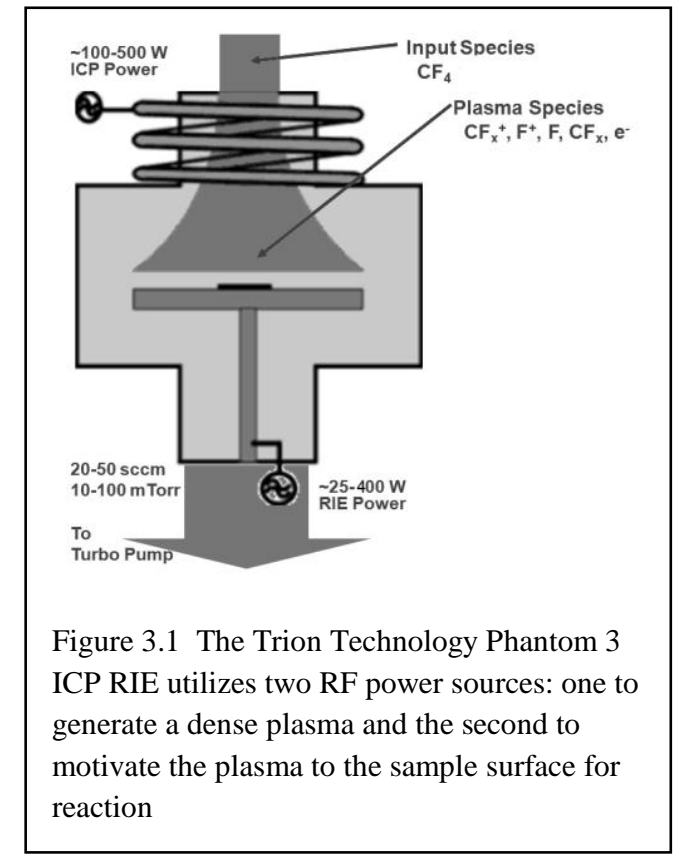
the $\mathrm{SiC}$ wafers were degreased in trichloroethylene, acetone and methyl alcohol.

Immediately after annealing, samples were removed from vacuum, and using a random order, placed into vials of benzene (Aldrich anhydrous, 99.8\%), nitrobenzene (Aldrich, 99.5\%), acetonitrile (Aldrich anhydrous, 99.8\%) or a ten millimolar solution of 4 nitrobenzenediazonium tetrafluoroborate (Aldrich, 97\%) in acetonitrile. The vials were kept in the dark for twenty hours before removal of the samples. Upon removal, the samples were washed with either benzene 
(for the benzene and nitrobenzene adsorption) or acetonitrile (for the acetonitrile and diazonium adsorption) and dried. The samples were then loaded into the UHV system for XPS analysis.

\subsection{X-RAY PHOTOELECTRON SPECTROSCOPY}

X-ray photoelectron spectroscopy (XPS) was accomplished with a Physical Electronics 5700 XPS system. Surface sensitive spectra, however, were acquired using a Physical Electronics VersaProbe 5000 system located in the WVU Shared Facilities. Both instruments have standard (Al/Mg filaments) and monochromated ( $\mathrm{Al}$ filament) sources. The monochromated $\mathrm{Al}$ source having an energy of $1486.6 \mathrm{eV}$ was used to obtain all spectrum

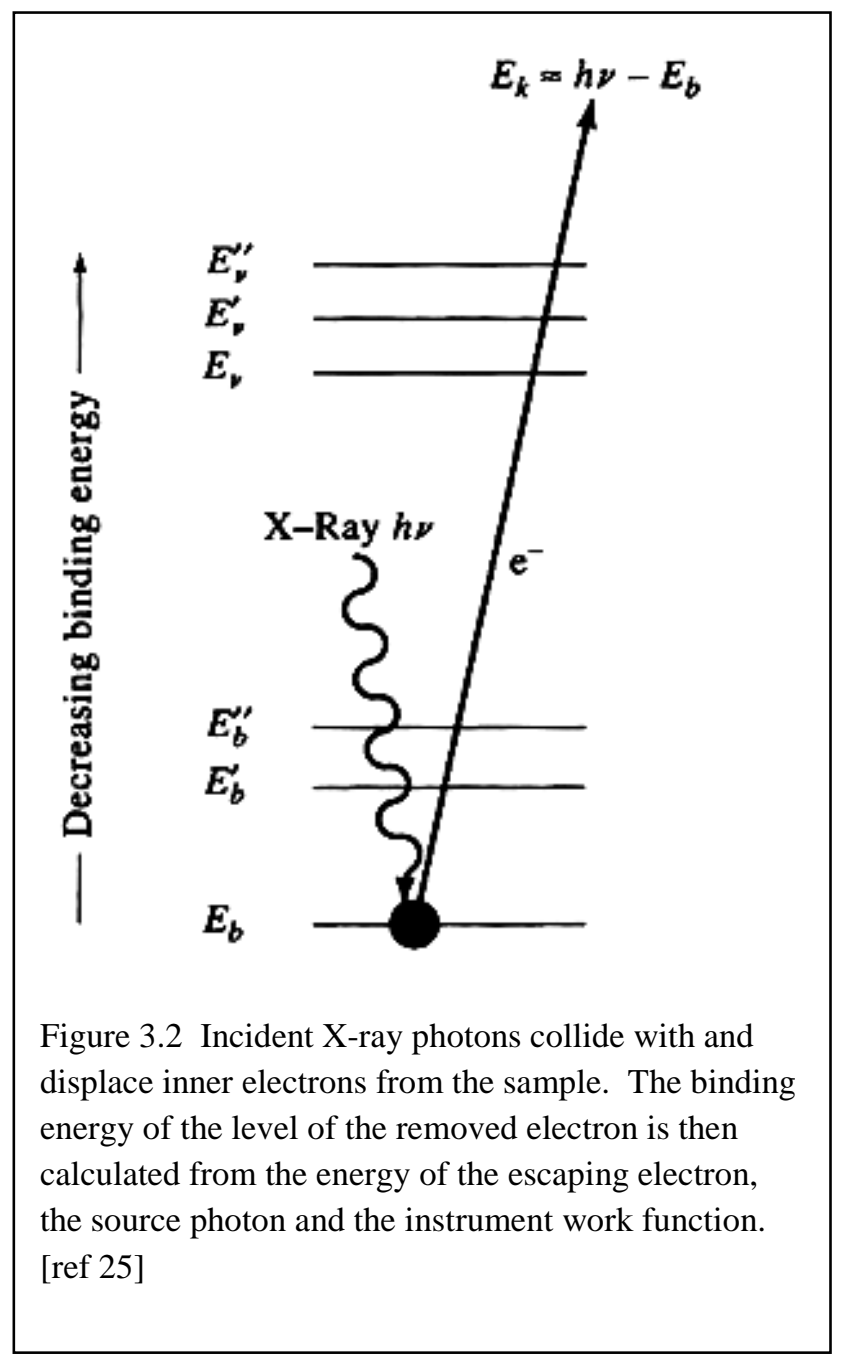
reported here. The system was calibrated using the Au XXX line at $84.0 \mathrm{eV}$. Sample charging, when it occurred, was taken into account by aligning the $\mathrm{C} 1$ s peak for the $\mathrm{SiC}$ substrate at $282.5 \mathrm{eV}$.

XPS has been historically called electron spectroscopy for chemical analysis (ESCA) as the technique gives information on both chemical (oxidation) state and atomic composition of samples. ${ }^{25}$ In XPS, monoenergetic photons of known energy $(h v)$ displace core electrons from atoms, molecules or ions as shown in figure 3.1. The kinetic energy of the displaced electron $\left(E_{k}\right)$ is 
measured by the spectrometer and the electron's binding energy $\left(E_{b}\right)$ is calculated based on conservation of energy, using the equation:

$$
E_{b}=\boldsymbol{h} v-E_{k}-w
$$

Here, $w$ is the work function of the spectrometer, which is taken into account during calibration of the changes in the instrument. Changes in chemical state of the atoms produce small shifts on the binding energies. These so called chemical shifts are well documented in the literature and used extensively in the present work. 


\section{CHAPTER 4}

\section{EXPERIMENTAL RESULTS AND DISCUSSION}

\subsection{THE PREPARED BUCKLED GRAPHENE SURFACE}

Figure 4.1 shows the $\mathrm{C}$ 1s XPS

peak for a $\mathrm{CF}_{4}$ etched $6 \mathrm{H}-\mathrm{SiC}$ surface. In

this case, the etch conditions were $400 \mathrm{~W}$

RIE, $300 \mathrm{~W}$ ICP, 25 mTorr and $20 \mathrm{sccm}$

of $\mathrm{CF}_{4}$ for 12 minutes. Similar conditions

were used for all samples in this study.

Deconvolution of this spectrum yielded

four peaks at $282.5 \mathrm{eV}, 283.8 \mathrm{eV}, 284.8$

$\mathrm{eV}$ and $287.9 \mathrm{eV}$. The $282.5 \mathrm{eV}$ peak is

tied to carbon in the $\mathrm{SiC}$ substrate. ${ }^{27}$ The

peak at $283.8 \mathrm{eV}$ corresponds with $\mathrm{sp}^{2}-\mathrm{C}$

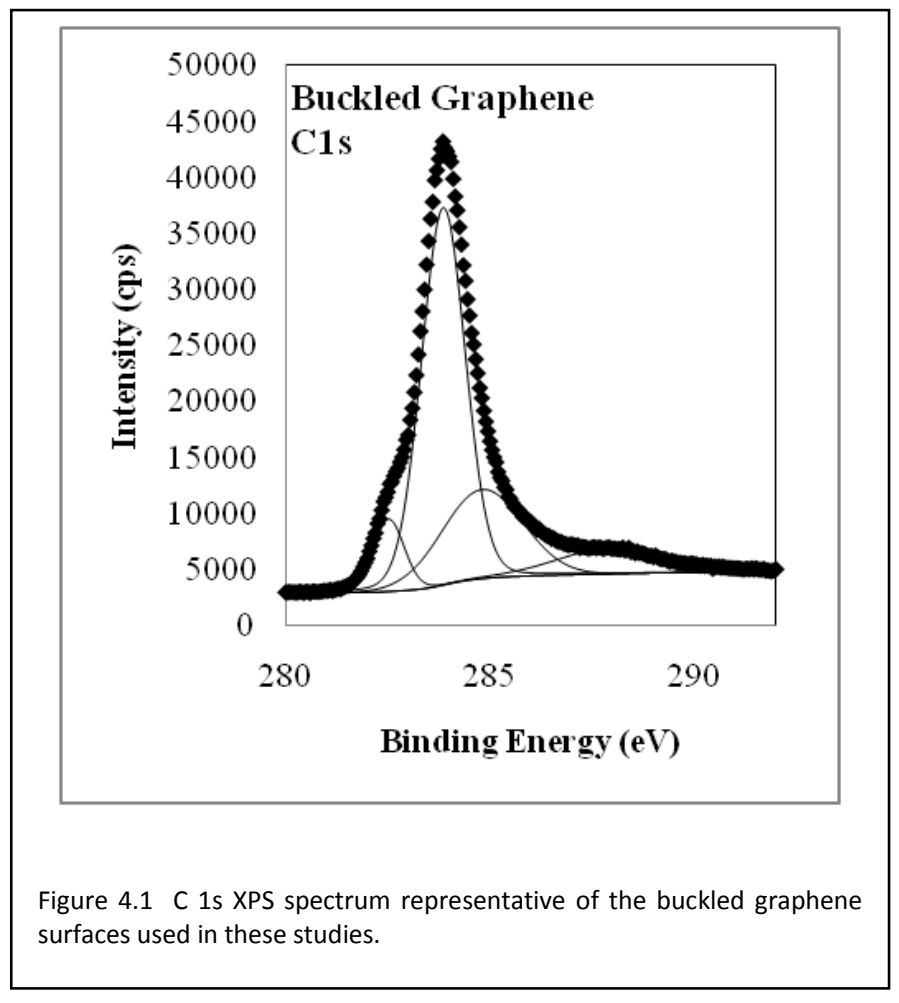

in p-doped graphene as shown by the F4-TCNQ p-doped graphene studied by Chen. ${ }^{16}$ The last two peaks originate in the p-doping of the material by fluorine as suggested by the experimental and computational studies reported by Sato. ${ }^{28}$ Specifically, the peak at $287.9 \mathrm{eV}$ corresponds to the $\mathrm{sp}^{3} \mathrm{C}$ atoms bound to $\mathrm{F}$ atoms and previously identified as $\mathrm{C}_{\mathrm{F}}$ species (see Figure 2.4). Likewise, the peak at $284.8 \mathrm{eV}$ corresponds to $\mathrm{sp}^{2}-\mathrm{C}$ atoms bound to the $\mathrm{sp}^{3}-\mathrm{C}$ atoms and previously identified as $\mathrm{C}_{\mathrm{C}}$ species.

Figure 4.2 shows the corresponding F 1s spectra which reveals two peaks, one at 685.0 $\mathrm{eV}$ and the other at $688.5 \mathrm{eV}$. These species are the result of the plasma process and correspond 
to F-atoms bound to the graphene. As

discussed later, the higher binding energy

peak corresponds to the F-atom above the

plane of the surface, and the lower binding

energy peak is due to the F-atom below the

surface. $^{10}$

\subsection{ADSORPTION OF BENZENE}

Figure 4.3 shows the C 1s XPS peak

after the buckled graphene has been reacted

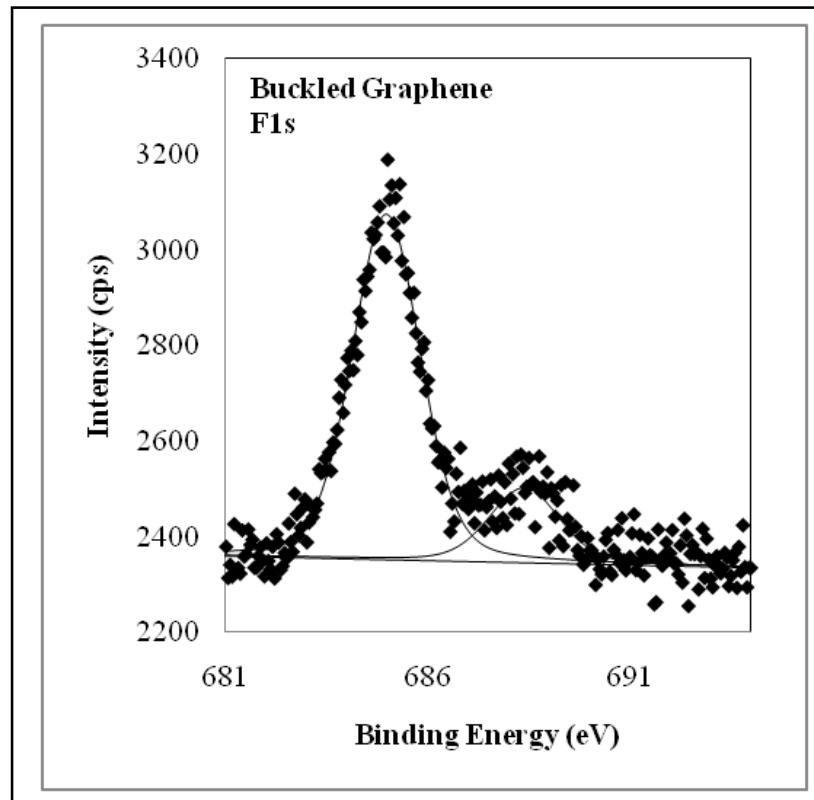

Figure 4.2 F 1s XPS spectrum representative of the buckled graphene surfaces used in this study.

with benzene. Deconvolution of this peak reveals components at $282.5 \mathrm{eV}, 283.7 \mathrm{eV}, 284.8 \mathrm{eV}$, $286.5 \mathrm{eV}$, and $288.6 \mathrm{eV}$. As before, the $\mathrm{SiC}$ carbon peak was found at $282.5 \mathrm{eV}$ and the p-doped graphene peak at $283.7 \mathrm{eV}$. The $0.1 \mathrm{eV}$ shift in the latter peak may reflect a slight change in the level of p-type doping of the buckled graphene.

The peak at $284.8 \mathrm{eV}$ corresponds to the $\mathrm{C}_{\mathrm{C}}$ peak as previously discussed.

However, compared to the $\mathrm{C}_{\mathrm{C}}$ peak shown in Figure 4.1, this peak has a significantly increased intensity. This is most likely due to the adsorption of a well defined species with comparable C 1s binding energy, and in this case, the most likely candidate is $\mathrm{C}_{6} \mathrm{H}_{6}$.

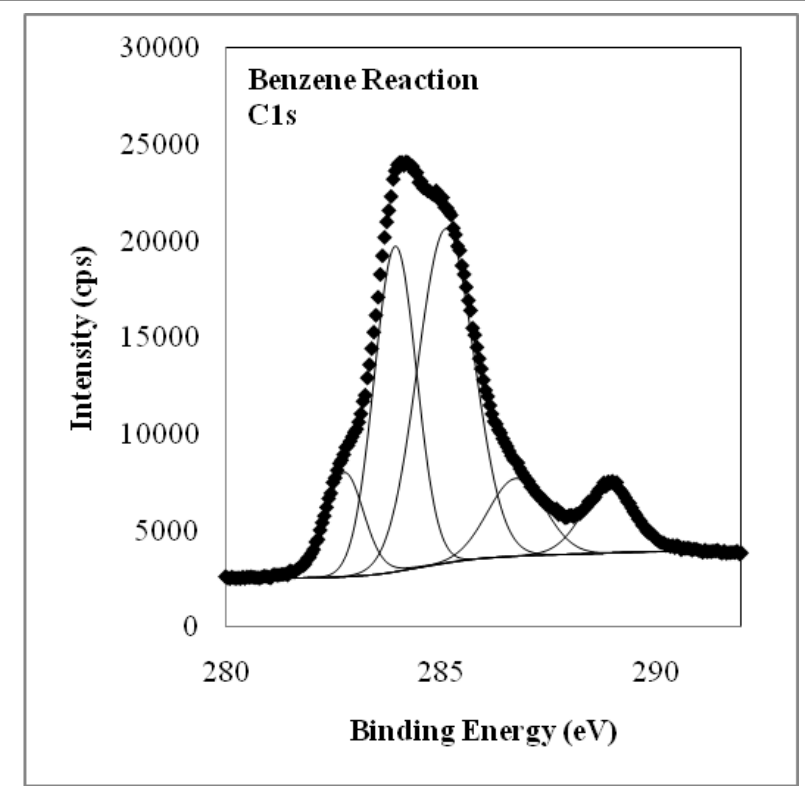

Figure 4.3 C 1s XPS spectrum observed after the reaction of buckled graphene with nitrobenzene. 
Briggs and $\mathrm{Seah}^{29}$ place the $\mathrm{C}_{6} \mathrm{H}_{6}$ peak at $284.7 \mathrm{eV}$. This is in reasonable agreement with our peak at $284.8 \mathrm{eV}$. In this case, the interaction of the $\mathrm{C}_{6} \mathrm{H}_{6}$ with the buckled graphene surface most likely involves $\pi$ - $\pi$ stacking. That is, an interaction between the $\pi$-electrons of the ring and the buckled graphene surface.

The peak at $286.5 \mathrm{eV}$ may correspond to $\mathrm{C}_{6} \mathrm{H}_{5} \mathrm{~F}$. As noted by Sundberg and coworkers, ${ }^{30}$ fluorobenzene has a $\mathrm{C} 1 \mathrm{~s}$ peak nominally in this position. In this case, the ring would lie in a plane normal to the surface.

The peak at $288.6 \mathrm{eV}$ may correspond to $\mathrm{C}_{6} \mathrm{~F}_{6}$. Wagner et al. ${ }^{31}$ indicate that the $\mathrm{C} 1 \mathrm{~s}$ peak for this species is at $288.3 \mathrm{eV}$, which would be a reasonable match. Although it is tempting to make this assignment, it is difficult to believe that there is enough mobility for adsorbed $\mathrm{C}_{6} \mathrm{H}_{6}$ molecules to scavenge $\mathrm{F}$-atoms in this way. An alternative and more likely species is $\mathrm{C}=\mathrm{O}$. Romaschin et al. ${ }^{32}$ place the $\mathrm{C} 1 \mathrm{~s}$ for this species at $288.5 \mathrm{eV}$, which is in reasonable agreement with our peak at $288.6 \mathrm{eV}$. A similar species was observed by Bekyarova et al. ${ }^{12}$ in their studies of nitrophenyl diazonium adsorbed on graphene; although they place the peak at slightly lower binding energy.

The corresponding F 1s data for the benzene functionalized surface is shown in Figure 4.4. This spectrum is very similar to that of the bare material in that two distinct peaks are present. The low binding energy peak corresponding to the subsurface species is at $685.0 \mathrm{eV}$ as for buckled graphene. This is not surprising for the subsurface peak, which should not interact with the adsorbed $\mathrm{C}_{6} \mathrm{H}_{6}$. The higher binding energy peak is located at $687.8 \mathrm{eV}$. That is, it is downshifted by $0.7 \mathrm{eV}$ from that for the bare surface. This would be consistent with the bonding of the $\mathrm{C}_{6} \mathrm{H}_{6}$ to the surface through the surface F-atom (i.e., the $\mathrm{F}_{-} \mathrm{C}_{6} \mathrm{H}_{5}$ species). Specifically, 
since this F-atom can draw charge from both the underlying $\mathrm{C}_{\mathrm{F}}$ and $\mathrm{C}_{6} \mathrm{H}_{5}$ surface moiety this added electronic charge should act to lower the binding energy of the F $1 \mathrm{~s}$ peak.

In summary, it appears that the benzene interacts with the buckled graphene surface through $\pi-\pi$ stacking (i.e., the $\mathrm{C} 1 \mathrm{~s}$ peak at $284.8 \mathrm{eV}$ ) and also by forming a bond with the surface F species. (i.e., the $\mathrm{C} 1 \mathrm{~s}$ peaks at $286.5 \mathrm{eV}$ ). Of these

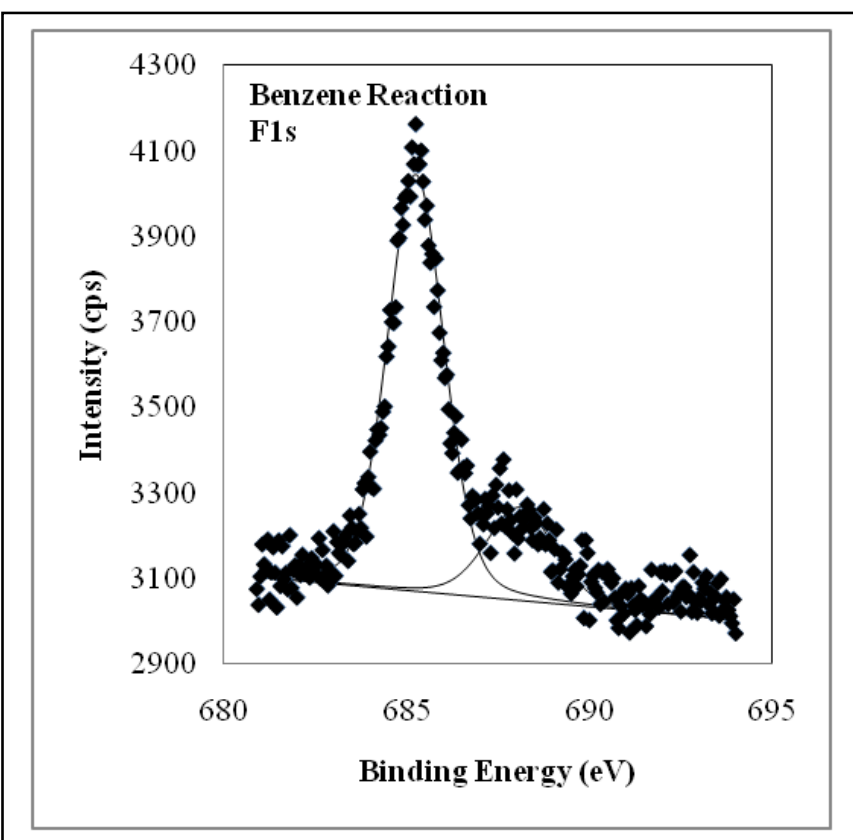

Figure 4.4 F 1s XPS spectrum observed after the reaction of buckled graphene with benzene.

two surface species, the latter is unique to buckled graphene, while the former might readily be observed on exfoliated graphene. The origin of the $\mathrm{C}=\mathrm{O}$ species (i.e., the $\mathrm{C} 1 \mathrm{~s}$ peak at $288.6 \mathrm{eV}$ ) is not clear.

\subsection{NITROBENZENE}

The C1s data for the

nitrobenzene reaction is somewhat

different from that of benzene; however, there are several similar features.

Deconvolution of this peak reveals components at $282.5 \mathrm{eV}, 283.9 \mathrm{eV}$, $285.0 \mathrm{eV}, 286.9 \mathrm{eV}$, and $288.5 \mathrm{eV}$.

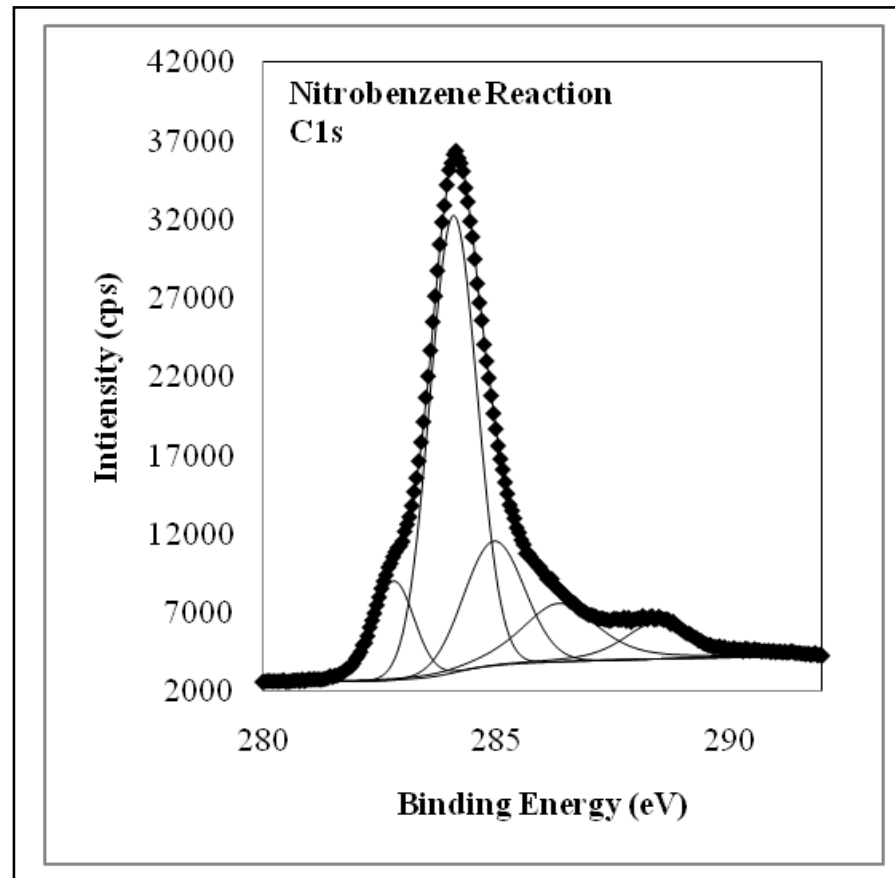

Figure 4.5 C 1s XPS spectrum observed after the reaction of buckled graphene with nitrobenzene. 
Peaks for $\mathrm{SiC}$ and graphene again are found at $282.5 \mathrm{eV}$ and $283.9 \mathrm{eV}$. The small $(0.1 \mathrm{eV})$ up shift in the graphene peak at $283.9 \mathrm{eV}$ could simply mean a slight change in the level of p-type doping.

The peak at $285.0 \mathrm{eV}$ can again be attributed again to the overlap of the $\mathrm{C}_{\mathrm{C}}$ species and $\pi$ $\pi$ stacking interaction of the graphene with the adsorbed $\mathrm{C}_{6} \mathrm{H}_{5} \mathrm{NO}_{2}$ ring of the nitrobenzene molecule. The peak at $286.9 \mathrm{eV}$ can not be readily identified from standard spectra. The natural assignment would be for the $\mathrm{C}-\mathrm{NO}_{2}$ in the nitrobenzene, but the $\mathrm{C}$ 1s peak for this species nominally occurs at $285.9 \mathrm{eV} .{ }^{31}$ Bekyarova et al. ${ }^{12}$ suggest that the $\mathrm{NO}_{2}$ in nitrobenzene is reduced to $\mathrm{NH}_{2}$ by $\mathrm{x}$-ray irradiation, but even in this case, the $\mathrm{C}-\mathrm{NH}_{2}$ moiety has a $\mathrm{C} 1 \mathrm{~s}$ peak also in the range of $285.9 \mathrm{eV},{ }^{31}$ so this does not seem to be a possibility. A third possibility is that this peak corresponds to the nitrobenzene bound to the surface through the surface F-atom. This would be similar to case for benzene (e.g., $\mathrm{F}_{-} \mathrm{C}_{6} \mathrm{H}_{4} \mathrm{NO}_{2}$ in this case) but with the $\mathrm{C} 1 \mathrm{~s}$ peak upshifted by $0.4 \mathrm{eV}$. Of the three possibilities the latter seems most plausible. Results from the F 1s spectrum discussed below are consistent with this assignment. The peak at 288.5 $\mathrm{eV}$, as in the case of benzene is most likely due to $\mathrm{C}=\mathrm{O}$.

The F $1 \mathrm{~s}$ spectrum for the reaction of nitrobenzene is shown in Figure 4.6. The lower binding energy peak at $685.0 \mathrm{eV}$ due to the subsurface

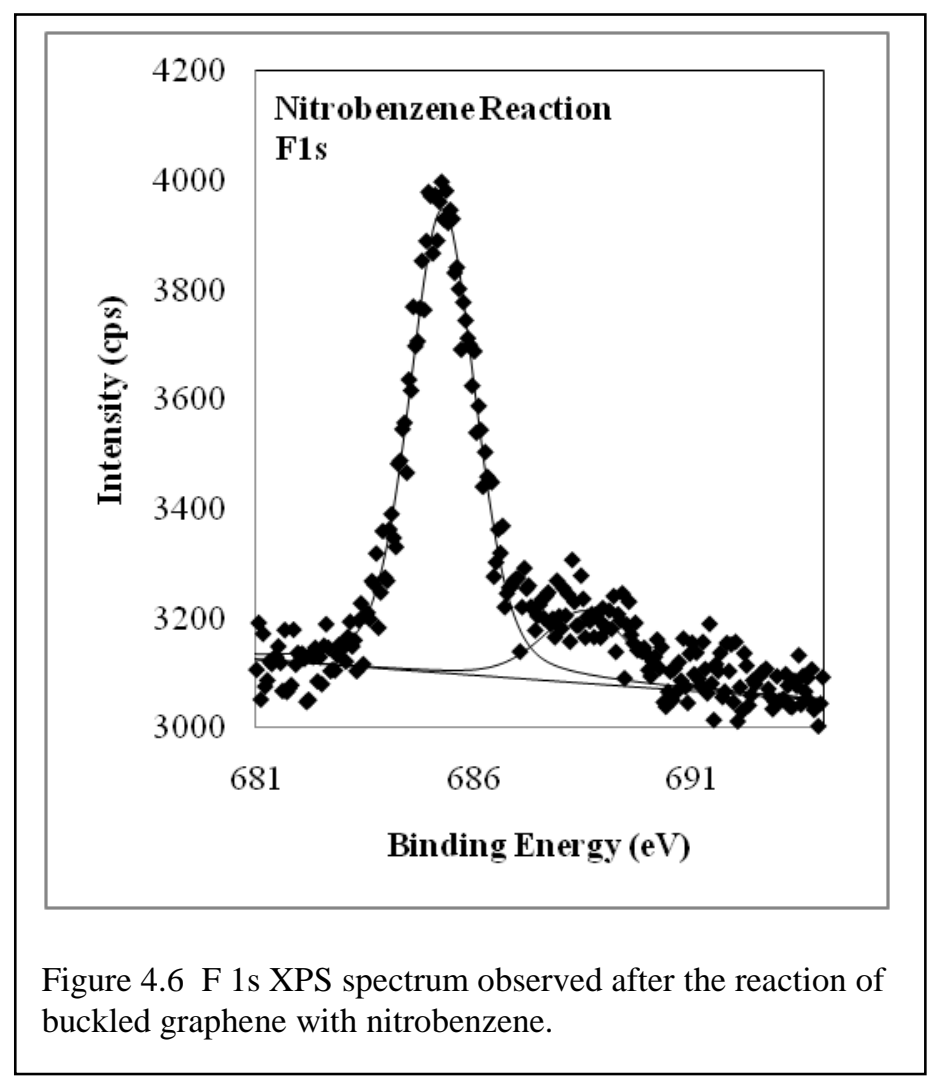


F-atom is unchanged. The higher

binding energy peak has been down shifted from 688 to $687.7 \mathrm{eV}$ is most

likely due to the interaction of the surface F-atom with the adsorbed nitrobenzene molecule. This is consistent with the observations for benzene adsorption. Interestingly, there is slightly less of the surface species here than in the case of both the bare surface and the adsorbed

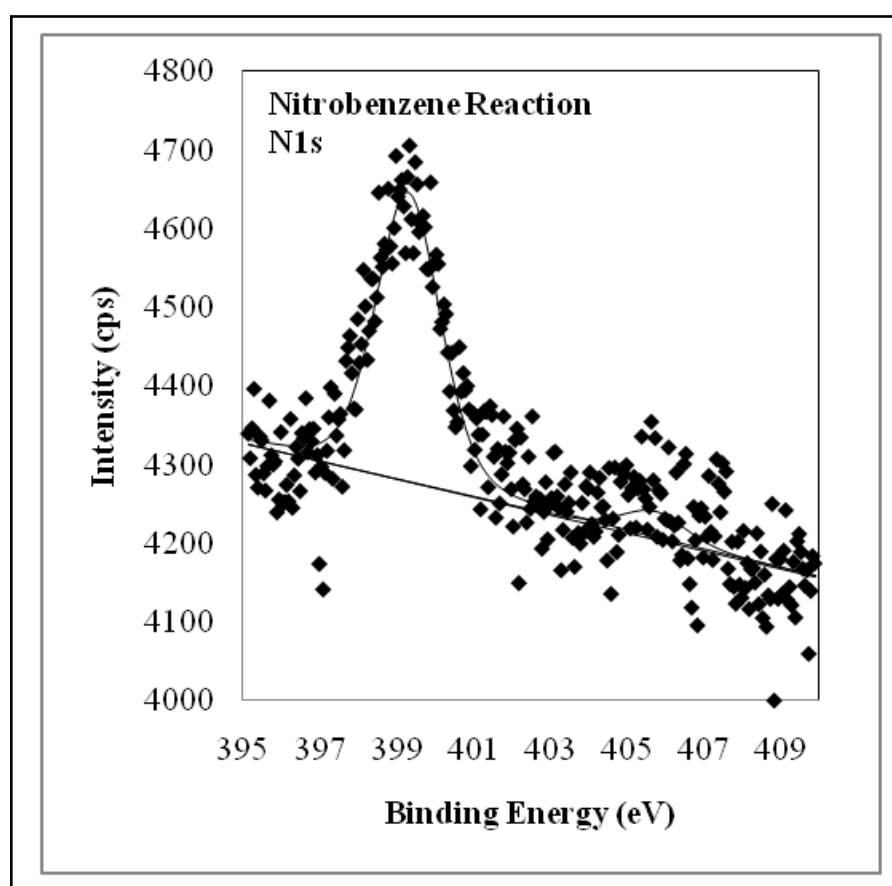

Figure 4.7 N 1s XPS spectrum observed after the reaction of benzene. This suggests that some of the surface fluorine has been desorbed in the reaction. As discussed later for the diazonium reaction, this may involve the formation of volatile NF species.

The N 1s XPS spectrum for the nitrobenzene reaction, shown in Figure 4.7, confirms the presence of nitrogen on the surface. The major peak at $399.0 \mathrm{eV}$ is most closely associate with amine groups, ${ }^{23}$ while the very slight peak at $405.7 \mathrm{eV}$ is the due to the nitro-group. As noted previously Bekyarova ${ }^{12}$ has suggested that the amines are formed by $\mathrm{x}$-ray irradiation of the nitro groups. This explains why a carbon species bound to a nitro group is not observed in the $\mathrm{C} 1 \mathrm{~s}$ spectrum, but it begs the question as to why not a carbon species bound to an amine.

\subsection{ADSORPTION OF ACETONITRILE}

The C 1s XPS spectrum for the buckled graphene surface after reaction with acetonitrile is shown in Figure 4.8. Deconvolution of this peak reveals components at $282.5 \mathrm{eV}, 283.6 \mathrm{eV}$, 
$284.3 \mathrm{eV}, 285.6 \mathrm{eV}$, and $288.1 \mathrm{eV}$. The peaks at $282.5 \mathrm{eV}$ and $283.6 \mathrm{eV}$ are again identified with the $\mathrm{SiC}$ substrate and the p-doped graphene, respectively. In this case, there is a $0.2 \mathrm{eV}$ downshift in the graphene peak which suggests an increase in the level of p-doping. As will be noted in the discussion of the F $1 \mathrm{~s}$ spectrum, the surface $\mathrm{F}$ level is higher on this sample than even the bare surface which would be consistent with the suggested enhanced p-doping. In the

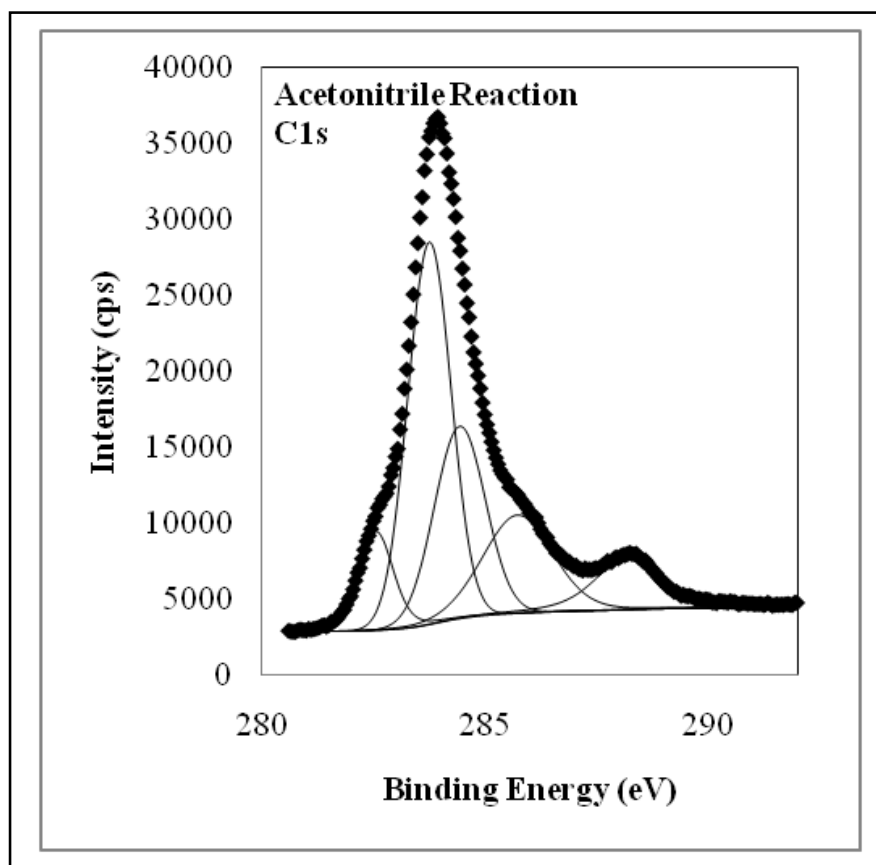

Figure 4.8 C 1s XPS sprctrum observed after the reaction of buckled graphene with acetonitrile.

same way, the peak at $284.3 \mathrm{eV}$ may be due to the $\mathrm{C}_{\mathrm{C}}$ species downshifted by $0.5 \mathrm{eV}$. The peak at $285.6 \mathrm{eV}$ is most likely due to a $\mathrm{CN}$ species. ${ }^{31}$ This is most likely the result of dissociative chemisorption on the resultant covalent bonding of the nitrile group to the surface. Finally, the $\mathrm{C} 1$ s peak at 288.1 is still most likely due to $\mathrm{C}=\mathrm{O}$ species.

The F 1s spectrum for the acetonitrile reaction is shown in Figure 4.9. Again two peaks, one at $684.9 \mathrm{eV}$ and the other at $688.3 \mathrm{eV}$, are observed. These peaks are essentially the same as those for the bare buckled graphene surface. As noted above, the surface fluorine peak is more intense here than in the typical buckled graphene case, which suggests a higher level of p-doping than usual. It appears that, in this case, somewhat less of the surface fluorine species were desorbed during the thermal anneal. The fact that these peaks occur at their normal energies suggests that the acetonitrile does not interact with the surface through the fluorine. This is 
distinctly different from the reactions for benzene and nitrobenzene in which the surface fluorine was involved in bonding the benzene ring.

The N 1s spectrum for the acetonitrile reaction is shown in Figure 4.10. For this spectrum only a single peak at $399.1 \mathrm{eV}$ is observed. This peak is associated with the nitrile group, ${ }^{23}$ which is consistent with the $\mathrm{CN}$ moiety at $285.6 \mathrm{eV}$ in the $\mathrm{C} 1 \mathrm{~s}$ spectrum.

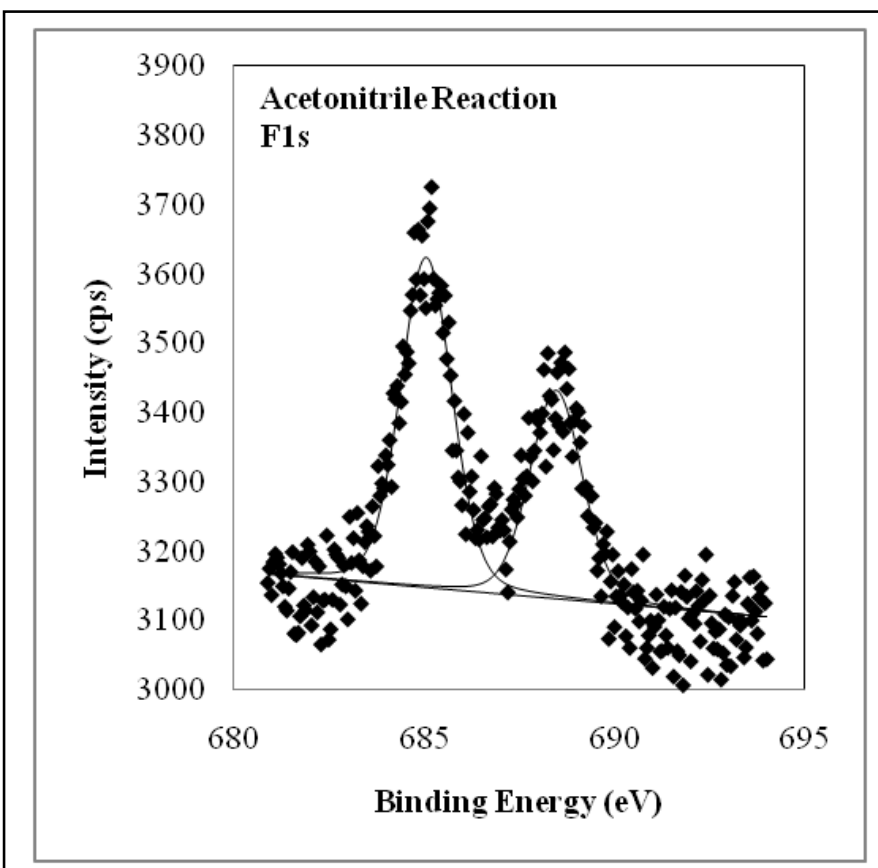

Figure 4.9 F 1s XPS sprctrum observed after the reaction of buckled graphene with acetonitrile.

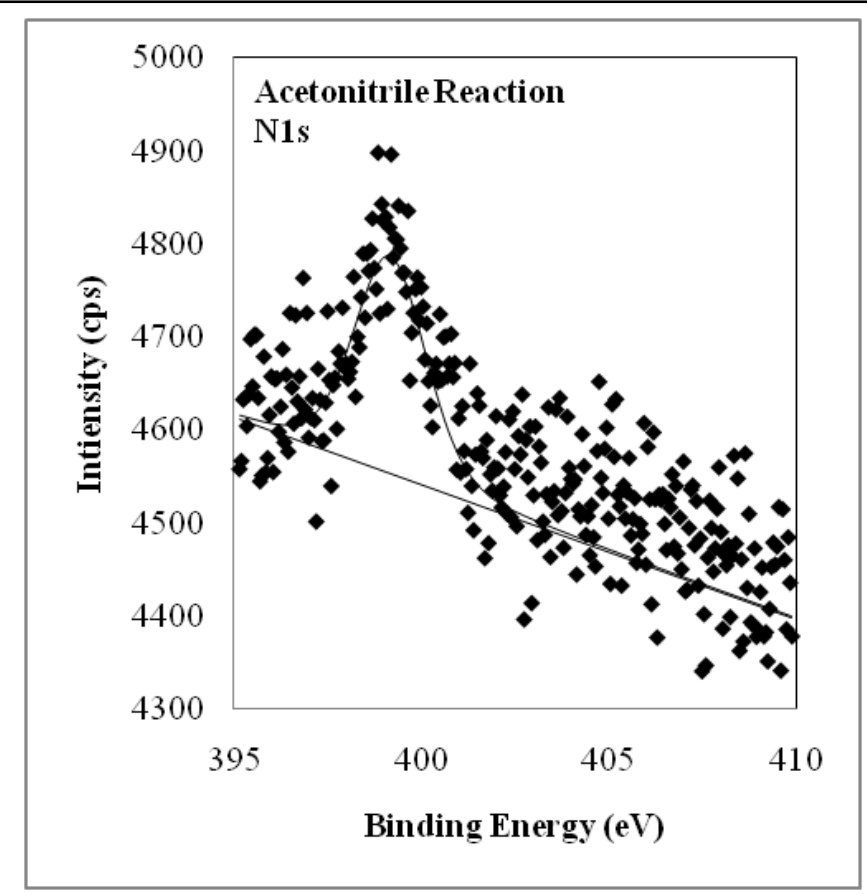

Figure 4.10 N 1s sprctrum observed after the reaction of buckled graphene with acetonitrile. 


\subsection{ADSORPTION OF NITROBENZENEDIAZONIUM TETRAFLUOROBORATE}

Figure 4.11 shows the $\mathrm{C} 1 \mathrm{~s}$

spectrum of the graphene following the diazonium reaction. Deconvolution of this peak reveals five components at $282.5 \mathrm{eV}, 283.7 \mathrm{eV}, 284.7 \mathrm{eV}, 286.0 \mathrm{eV}$, and $288.5 \mathrm{eV}$. These components and the overall peak shape are very similar to the case for benzene reaction. The SiC and graphene peaks are located at 282.5 $\mathrm{eV}$ and $283.7 \mathrm{eV}$, respectively.

The $\mathrm{C} 1 \mathrm{~s}$ peak at $284.7 \mathrm{eV}$

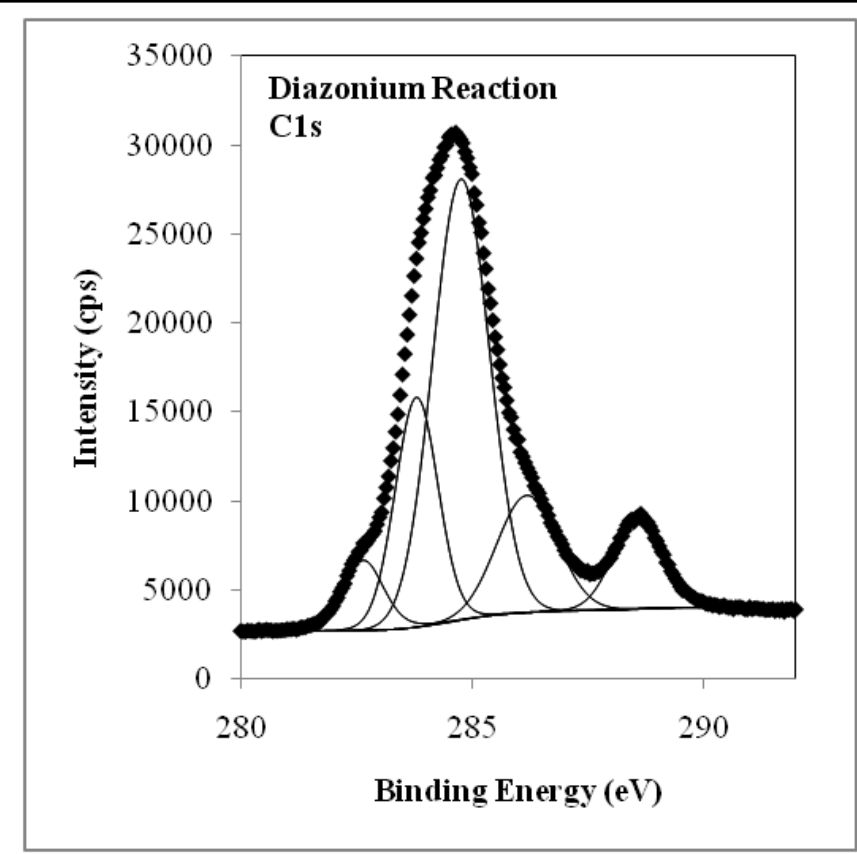

Figure 4.11 C 1s XPS spetrum observed after the reaction of buckled graphene with diazonium. (may want to refit this )

corresponds to the overlap of the $\mathrm{C}_{\mathrm{C}}$ and $\pi-\pi$ stacked $\mathrm{C}_{6} \mathrm{H}_{6}$ species as before. The peak at $286.0 \mathrm{eV}$ corresponds to the $\mathrm{C}$ $\mathrm{NO}_{2}$ or nitro species observed by Bekyarova. $^{12}$ It is not clear form XPS if this is associated with the $\pi-\pi$ stacked $\mathrm{C}_{6} \mathrm{H}_{5} \mathrm{NO}_{2}$, or with a covalently bound C$\mathrm{C}_{6} \mathrm{H}_{4} \mathrm{NO}_{2}$. The infrared spectroscopy results of Bekyarova ${ }^{12}$ suggest that covalent bonding is the primary attachment mode.

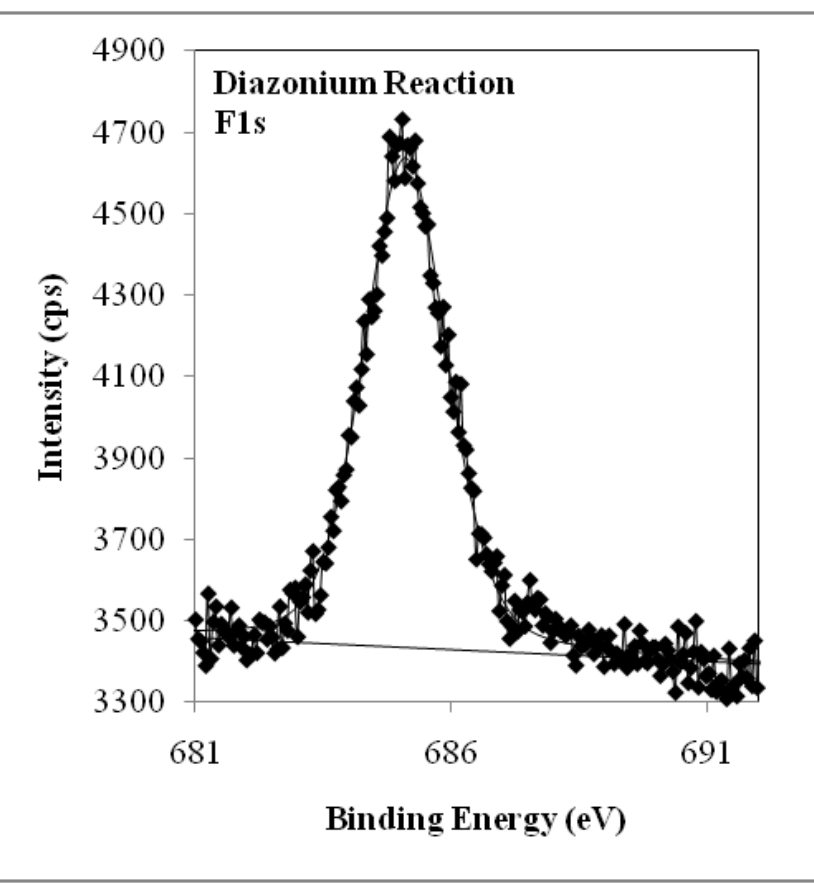

Figure 4.12 F 1s XPS peak observed after the reaction of buckled graphene with diazonium. 
As seen in Figure 4.12 the F 1s XPS peak for the diazonium reaction shows only one peak at $685.0 \mathrm{eV}$. This peak was shown earlier to correspond with fluorine on the underside of the graphene top layer. The higher energy surface peak was completely removed in the reaction. The removal of ionic fluorine by this suggests an $S_{N} 1$ type reaction in which the fluorine group leaves the surface and is replaced by the

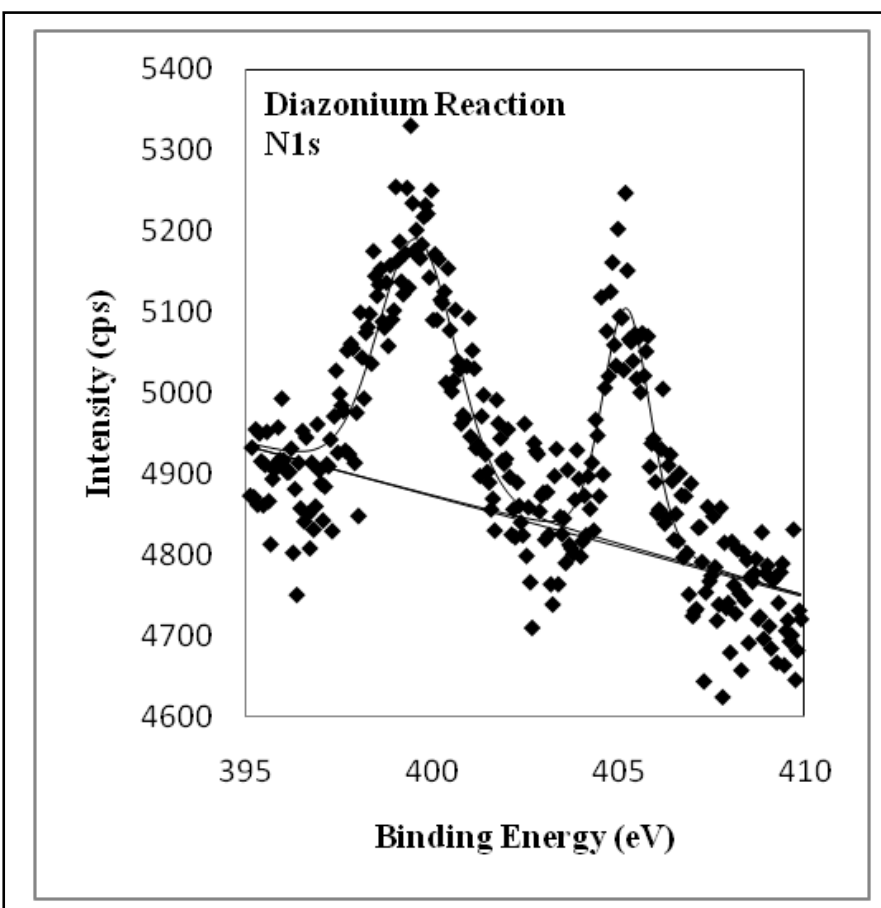

Figure $4.13 \mathrm{~N}$ 1s XPS peak observed after the reaction of buckled graphene with diazonium. nitrophenyl group. This would be consistent with the covalent bonding scheme observed by Bekyarova $^{12}$ with displacement of the surface $\mathrm{F}$ atom. Similar reactions involving the fluorinated surface of exfoliated graphene and hydrazine $\left(\mathrm{N}_{2} \mathrm{H}_{4}\right)$ have been observed by Robinson et al. ${ }^{33}$ Here, it is thought that the surface fluorine is removed by the formation of volatile NF species.

The N1s XPS spectrum for the diazonium reaction is shown in Figure 4.13. Deconvolution of this spectrum reveals two peaks, one at o $399.1 \mathrm{eV}$ and the other at $405.0 \mathrm{eV}$. As discussed previously, the peak at $399.0 \mathrm{eV}$ corresponds with the amine group while the peak at $405.5 \mathrm{eV}$ corresponds with the nitro group. This is similar to was observed to the reaction with the nitrobenzene reaction. 


\subsection{IMPLICATIONS OF THIS RESEARCH}

The development of sensors and molecular electronics using buckled graphene produced by the present synthesis method is dependent on several factors. The first of these relates to the electrical properties of these films. In separate studies, Denig ${ }^{11}$ has shown that the buckled graphene films have an electrical conductivity and carrier density comparable to exfoliated graphene. Moreover, it has been shown that metal contacts with low interfacial resistance can be produced. Thus, the first of the criteria has been met.

The second requirement is that the surface of buckled graphene can be functionalized. This is necessary for both tailoring the doping levels of the film and for attaching molecules which possess either biological activity, electrical conductivity, or other physical attributes. The studies presented here represent a first step in demonstrating and characterizing the functionalization of the buckled graphene surface.

It is interesting that as work for this thesis draws to a close, other groups are beginning to look at fluorination of normal graphene surfaces as a means of opening "robust" pathways for molecular additions. ${ }^{33}$ Thus the presence of these "defects" on the buckled graphene surface may prove advantageous for functionalization processes. It is clear that halogens other than $\mathrm{F}$ and $\mathrm{Cl}$ can be used (eg. Br) ${ }^{\text {Frandlich }}$, and this may open a range of reaction pathways.

The results presented here have identified $\pi-\pi$ stacking for benzene, nitrobenzene, and diazonium. In addition, the possibility of a covalently bound $\mathrm{C}-\mathrm{C}_{6} \mathrm{H}_{4} \mathrm{NO}_{2}$ species has been observed in the case of diazonium interaction. The $\pi-\pi$ interaction should be possible on both buckled and exfoliated graphene. The covalent bond may require the displacement of the surface $\mathrm{F}$ atom. In addition, we have observed bonds unique to the buckled graphene in the formation of F- $\mathrm{C}_{6} \mathrm{H}_{5}$ covalent bonds for benzene and nitrobenzene. 
The last example, that of the diazonium reaction, is the most promising due to the displacement of $\mathrm{F}$ from the surface and the implications of the formation of a strong covalent bonds. Similar reactions, such as the butyl amine reaction shown by Bon ${ }^{18}$ should be possible. The importance of the diazonium reaction is two-fold. First this reaction presents a pathway toward sensing materials and molecular electronics. Second, the removal of only the high binding energy $\mathrm{F}$ 1s peak in the diazonium reaction corroborates the association of this peak with the surface fluorine. The fact that the lower binding energy peak remained unchanged in all reactions confirms its association with the subsurface fluorine. Taken together, these results for the diazonium reaction substantially validate the buckled model of our graphene surfaces. Finally, by inference from these results, it is possible to suggest strongly nucleophilic groups for $\mathrm{S}_{\mathrm{N}} 1$ type reactions with the buckled graphene surface. 


\section{CHAPTER 5}

\section{CONCLUSIONS AND FUTURE WORK}

\subsection{CONCLUSIONS}

The research presented here fills two purposes. The first is to aid in the characterization of buckled graphene prepared by the plasma fluorination of $\mathrm{SiC}$. The second is to functionalize the surface of this new material. The latter is a critical first step in the development of chemical and biochemical sensors as well as molecular electronics device structures using buckled graphene. The basic approach uses XPS to characterize the bonding of 4-nitrobenzenediazonium to the surface. In order to fully understand this interaction, it was necessary also investigate the bonding of benzene, nitrobenzene, and acetonitrile to the buckled graphene surface. These studies revealed the importance of several bonding modes including $\pi-\pi$ van der Waals bonding as well $\mathrm{C}$ (surface) $-\mathrm{C}$ and $\mathrm{F}$ (surface)-C covalent bonding of the benzene ring. Evidence reflecting shifts in the level of p-type doping due to molecular attachment was observed. Finally, it was observed that surface $\mathrm{F}$ atoms could be removed by the interaction of 4-nitrobenzenediazonium.

All adspecies containing the benzene ring exhibited $\pi$ - $\pi$ stacking as well as covalent bonding to the surface the surface. For benzene and nitrobenzene, covalent bonding of the ring through the surface $\mathrm{F}$ atom is observed. In this case the ring is normal to the surface rather than parallel to the surface as is the case for $\pi$ - $\pi$ stacking. In the case of 4-nitrobenzenediazonium, covalent bonding of the ring with a surface $\mathrm{C}$ atom and the elimination of the surface $\mathrm{F}$ atom is observed. Again the ring should be normal to the surface in this configuration. This reaction is 
also quite useful in confirming the assignment of the surface and subsurface XPS peaks and thereby strengthening the spectroscopic characterization of the structure of the $\mathrm{C}_{\mathrm{C}}-\mathrm{C}_{\mathrm{F}}$ defect.

The adsorption of 4-nitrobenzenediazonium and not nitrobenzene or benzene leads to desorption of the surface fluorine. This is clear evidence of the importance of the diazo group in removing the surface $\mathrm{F}$ atoms. This may have applications in both functionalizing the surface as well as altering the doping level of the graphene film. As literature suggests, this reaction takes place on graphene surfaces without the fluorine defect, however the complete removal of the out of surface fluorine suggests the preferential reaction at this defect site.

A shift in the $\mathrm{C} 1 \mathrm{~s}$ binding energy for the p-type graphene was observed after the adsorption of each molecular species. As discussed, this suggests that the adsorption process alters the doping of the film. This is critical if electrical properties are to be tailored.

The diazonium reaction in this research places a nitrophenyl group on the carbon surface, which necessitated the additional trial of pure nitrobenzene with the buckled graphene. This test gave results very similar benzene, but with and up shift in the binding energy of the $\mathrm{C} 1 \mathrm{~s}$ photoelectron. This directly relates to the electron withdrawing nitro group within the nitrobenzene, and corresponds with literature reports. Nitrobenzene behaves very similarly to benzene on the buckled graphene surface, which is understandable given the similar structure. The importance of this data is, again, not the presence of nitrobenzene on the surface but the difference between this spectrum and that following the diazonium reaction.

Acetonitrile was studied due to its role as the solvent of the diazonium salt. While future studies may find a solvent which does not remain on the carbon surface, acetonitrile remains. It causes a down shift in the $\mathrm{C} 1 \mathrm{~s}$ peak for $\mathrm{p}$-type graphene and the formation of residual nitrile species on the surface. 
The reaction with 4-nitrobenzenediazonium tetrafluoroborate was chosen in part due to the recent study of the salt with thermally annealed graphene. ${ }^{12}$ The Bekyarova $\mathrm{C} 1 \mathrm{~s}$ post reaction spectrum shows a broad peak at $285.57 \mathrm{eV}$, associated with the $\mathrm{C}-\mathrm{N}$ bond within the nitro-phenyl group, and a peak at $283.45 \mathrm{eV}$ from newly p-doped graphene. This differs significantly from the carbon spectra of this research; this difference is attributed to the buckled graphene starting material. The graphene used by Bekyarova was not initially p-doped, and the p-doping by the into-plane fluorine contributes significantly to the difference in the amount of functionalization of the buckled graphene surface. The second contributing factor is the presence of the out of plane F defect sites, which serve as reaction sites for the salt.

The diazonium reaction characterizes the buckled graphene surface beyond what was done by surface sensitive XPS by the complete removal of only the higher binding energy F 1s peak. This further identifies the carbons bound to fluorine as $\mathrm{sp}^{3}$ hybridized. While the $\mathrm{sp}^{2}$ carbon of benzene, graphite and graphene is planer in structure, $\mathrm{sp}^{3} \mathrm{C}$ assumes a tetragonal structure to minimize the energy of the molecule. The energy of the structure is further reduced by incorporating pairs of defects; out of surface $\mathrm{F}$ atoms pair with inter-planer $\mathrm{F}$ atoms.

The reaction at the out of surface fluoride site by the diazonium salt provides an excellent pathway for the functionalization of graphene by molecules other than the nitrobenzene group. First the reaction does not depend on the nitro group, which may be replaced by any $\mathrm{R}$ group. An active $\mathrm{R}$ group may be reacted to the ring either before the attachment of the ring to the graphene surface, or after. The nitro group was chosen due to ease of acquisition and relevant recent research; however, other groups with more desirable reaction pathways should yield similar results. 
The reaction at the F defect supports the work of Bon, et al., ${ }^{23}$ and begs the use of nucleophilic groups to react this surface. That both the butylamine and diazonium salt reaction favor the functionalization of the surface of the defect site proves the utility of this defect to future research in the development of nanoscale sensors and molecular electronics. The diazonium reaction is an important tool for the functionalization of graphene, but the fluorine doping of the material outshines the salt by yielding greater extent of reaction compared with undoped material, and a site for reactions other than those involving diazonium salts.

The purpose of this research was to functionalize buckled graphene using several molecular groups and to characterize the new material. This was accomplished by the use of four molecular species: benzene, nitrobenzene, acetonitrile and 4-nitrophenyldiazonium tetrafluoroborate. All four species interacted with the graphene surface, the last reacting away surface $\mathrm{F}$ atoms to covalently attach the nitrophenyl group. The diazonium reaction further supported the result of the surface sensitive XPS which suggested that the higher energy peak of the F 1s spectrum is due to an out of surface F atom.

\subsection{FUTURE WORK}

Much work remains for the development of nanoscale sensors and molecular electronics. The material made in this research requires further testing to determine the effects of molecular attachment on electrical properties and how they differ from the bare material. Further work is required to build a sensor platform on the graphene surface. The contribution of this thesis is a pathway; by the addition of a strong nucleophilic group to molecules such as conductive proteins, new sensing materials may be reacted onto the buckled graphene surface. The nucleophilic groups will react with graphene, as described in this thesis, leaving a sensing 
material attached to the graphene surface. From this point, changes in conductivity indicate responses of the active group. 


\section{REFERENCES}

1. http://minerals.usgs.gov/ds/2005/140/graphite-use.pdf

2. Geim, A. K. A. H. MacDonald, Phys. Today 60, 35 (2007)

3. Peierls, R. E. Quelques proprietes typiques des corpses solides. Ann. I. H. Poincare 5, 177$222(1935)$.

4. Landau, L. D. Zur Theorie der phasenumwandlungen II. Phys. Z. Sowjetunion 11, 26-35 (1937)

5. Geim A. K., K. S. Novoselov, Nat. Mater. 6, 183 (2007).

6. Novoselov, K. S., Geim, et al. Science 306, 666-669. (2004)

7. http://nobelprize.org/nobel_prizes/physics/laureates/2010/

8. W. Chen, S. Chen, D.C. Qi, X. Gao, A.T.S. Wee, Progress in Surface Science, 84 (2009) 279-321.

9. Castro Neto A. H., F. Guinea, N. M. R. Peres, K. S. Novoselov, and A. K. Geim, Rev. Mod. Phys. 81, 109 (2009).

10. Raghavan, S. Masters Thesis, WVU 2010.

11. Denig, T. Doctorial Defense, WVU 2010.

12. Bekyarova, E.; Itkis, M. E.; Ramesh, P.; Berger, C.; Sprinkle, M.; De Heer, W. A.; Haddon, R. C. J Am Chem Soc 2009, 131, 1336.

13. Khan M.A, M.A. Mukaddam, U. Schwingenschlögl. Chemical Physics Letters; 498, 157161. (2010).

14. Charrier A., A. Coati, T. Argunova, F. Thibaudau, Y. Garreau, R. Pinchaux, I. Forbeaux, J.M. Debever, M. Sauvage-Simkin, and J.M. Themlin; J. Appl. Phys. 92, 2479 (2002).

15. S.J. Sque, R. Jones, P.R. Briddon, Phys. Stat. Sol. (a) 204 (2007) 3078-3084. 
16. W. Chen, S. Chen, D.C. Qi, X. Gao, A.T.S. Wee. J. Am. Chem. Soc., 129, 10418-10422, (2007).

17. Blochwitz, J.; Pfeiffer, M.; Fritz, T.; Leo, K. Appl. Phys. Lett. 1998, 73,729.

18. Takenobu, T.; Kanbara, T.; Akima, N.; Takahashi, T.; Shiraishi, M.; Tsukagoshi, K.;

Kataura, H.; Aoyagi, Y.; Iwasa, Y. AdV. Mater. 2005, 17, 2430.

19. Harada, K.; Werner, A. G.; Pfeiffer, M.; Bloom, C. J.; Elliott, C. M.; Leo, K. Phys. ReV. Lett. 2005, 94, 036601.

20. Denis P., Iribarne F., Mombru A., ChemPhysChem 2009, 10, 715 - 722

21. Denis P., Iribarne F., International Journal of Quantum Chemistry, Vol 110, 1764-1771 (2010)

22. Stone, Wales, Chemical Physics Letters. 128, 5-6, August 1986, 501-503.

23. Bon S., Valentini L., Verdejo R., Fierro J., Peponi L., Lopez-Manchado M., and Kenny J. Chem. Mater.; 2009, 21, 3433-3438.

24. Peng, C.Y. Ph.D. Dissertation WVU 2004.

25. Skoog D.A., F.J. Holler, Nielman T.A. Principles of Instrumental Analysis. $5^{\text {th }}$ ed., Phillidelphia PA: Saunders College Publishing, 1998.

26. Silverstein R., F. Webster. Spectrometric Identification of Organic Compounds. $6^{\text {th }}$ ed., New York NY: John Wiley and Sons, Inc., 1998.

27. Contarinia, Howletta, Rizzoa, De Angelisa. Applied Surface Science. 51, 3-4, Sept. 1991, 177-183.

28. Sato, Itoh, Hagiwara, Fukunaga, Ito, Carbon 42. 3243-3249. 2004.

29. Briggs D., M.P. Seah. Practical Surface Analysis. New York NY: John Wiley and Sons, Inc., 1992. 
30. Sundberg, Larsson, Folkesson. Journal of Electron Spectroscopy and Related Phenomena 46, 1, 19-29, 1988.

31. Wagner C.D., J.W. Allison, J.R. Jr. Rumble, A.V. Naumkin, A. Kraut-Vass, C.J. Powell. Xray Photoelectron Spectros-copy Database. (version 3.0-3.4), National Institute of Standards and Technology (NIST), Gaithersburg, MD (2000-2003).

32. Romaschin A.D., L.N. Bui, M. Thompson, N.B. McKeown, P.G. Kalman. Analyst, Vol 118, 463-474, (1993).

33. Robinson, J.T., Burgess, J.S., C.E. Junkermeier, S.C.Badescu, T.L. Reinecje, F.K. Perkins, M.K. Zalalutdniov, J.W.Baldwin, J.C. Culbertson, P.E. Seehan, E.S. Snow, Nanoletters 10, 3001 (2010).

34. E. Stolyarova, et al. Proceedings of the National Academy of Sciences of the United States of America, 104, 22, 9209-9212, (2007)

35. Xiaolin Li, et al. Science 319. 5867, 1229 - 1232 (2008)

36. Berciaud, S., S. Ryu, L.E. Brus,T.F. Heinz, Nano Letters; 9, 1, p346-352 (2009)

37. Jansen, van Bekkum. Carbon, 33, 1021-1027 (1995).

38. Friedrich, J.F.; S. Wettmarshausen; S. Hanelt; R. Mach; R. Mix; E.B. Zeynalov; and A. Meyer-Plath, Carbon 48, 3884 (2010)

39. Sato, Y.; K. Itoh; R. Hagiwara; T. Fukunaga; and Y. Ito, Carbon 42, 3243 (2004)

40. Moreau, E., F. J. Ferrer, D. Vignaud, S. Godey, and X. Wallart, Phys. Status Solidi A 207, $300-303$ (2010). 